\title{
The potential of methylsiloxanes as solvents for synthetic chemistry applications
}

\author{
Mohd Azri Ab Rani, Nadine Borduas, Victoria Colquhoun, Robert Hanley, Henry Johnson, \\ Solène Larger, Paul D. Lickiss,* Veronica Llopis-Mestre, Selina Luu, Martin Mogstad, \\ Philipp Oczipka, James R. Sherwood, Tom Welton* and Jun-Yi Xing
}

Department of Chemistry, Imperial College, London SW7 2AZ, UK

E-mail: p.lickiss@imperial.ac.uk, t.welton@imperial.ac.uk

Received

The potential use of volatile methylsiloxanes (VMSs) as solvents for chemicals synthesis has been explored. Assessment of the environmental impact of these VMS solvents is made and found to be significantly lower than those of the non-polar organic solvents that they have the potential to replace. The polarities of the VMSs, as expressed by empirical polarity measurements, and miscibilities with other liquids are found to be similar to those of alkane solvents. Finally, some uses of VMSs as solvents for both organic and inorganic transformations are described. The VMSs provide environmentally more sustainable (greener) alternatives to the nonpolar solvents that they have the potential to replace.

\section{Introduction}

The sustainability of solvent use is being scrutinised by academia and industry alike with an ever increasing intensity. ${ }^{1-3}$ Such a high profile within green chemistry research can be justified by the volume of waste arising from industrial solvent use. ${ }^{4}$ It has been estimated that solvents accounted for $35 \%$ of all the volatile organic compounds (VOCs) that were released into the atmosphere from the UK in $2002^{5}$ and it is becoming increasingly apparent that minimising the impact of solvent use should be regarded amongst the highest of priorities within green chemistry.

The development of new classes of solvent, and the development of synthetic chemistry in these has been a significant area of research since green chemistry was first defined. ${ }^{6}$ Research utilising non-polar neoteric solvents is currently dominated by the use of supercritical carbon dioxide, ${ }^{7-9}$ and, to a lesser extent, fluorous solvents. ${ }^{10-12}$ Although these solvent systems have become popular the specialist equipment required to achieve supercritical conditions for $\mathrm{CO}_{2}$ and the modification of reaction components often required for compatibility with the fluorous phase are significant barriers to their wider application. These problems prompted us to explore the potential applications of other non-polar liquids as alternative solvents.

Volatile methylsiloxanes (VMSs) are well known compounds with a repeating silicon-oxygen backbone unit, with methyl group substituents. They have been given specific exemption from regulation as Volatile Organic Compounds (VOCs) in the USA ${ }^{13}$ and were approved to replace ozone-depleting substances such as methylchloroform under the Significant New Alternatives Policy, SNAP. ${ }^{14}$ In the corresponding European directive on VOCs no such exemptions have been granted for organic solvents with vapour pressures equal to or greater than $0.01 \mathrm{kPa}$ at 293.15 K. ${ }^{15}$ Poly(dimethylsiloxanes), PDMS, have negligible volatilities placing these safely outside of the requirements for 
VOC status in Europe. Siloxanes are ubiquitous, finding widespread use in a variety of applications, ${ }^{16-22}$ including antifoams, lubricants, adhesives, hydraulic fluids, and for degreasing clothes and circuit boards, ${ }^{23}$ yet their potential as solvents for use in synthetic chemistry has remained largely unexplored. There are, however, some scattered reports in the literature of siloxanes being used as reaction solvents, for example, the use of PDMS in the asymmetric hydrogenation of tiglic acid and poly(methylphenylsiloxane) as a solvent for the Ru-catalysed synthesis of $\mathrm{DMF},{ }^{23}$ the use of $\left(\mathrm{Me}_{3} \mathrm{Si}\right)_{2} \mathrm{O}$ as both reagent and solvent in glycosylation reactions, ${ }^{25}$ the use of $\left(\mathrm{Me}_{3} \mathrm{Si}\right)_{2} \mathrm{O}$ in the synthesis of an oxygen-centred hexatantalum cluster complex, ${ }^{26}$ together with several other examples as described below. There are also several examples of the use of $\left(\mathrm{Me}_{3} \mathrm{Si}\right)_{2} \mathrm{O}$, not as a reaction solvent, but as a solvent for recystallization. For example, the crystallization of $\left[\left(\eta^{5}-\mathrm{Me}_{5} \mathrm{C}_{5}\right)_{2} \mathrm{Co}\right]$ has been carried out in $\left(\mathrm{Me}_{3} \mathrm{Si}\right)_{2} \mathrm{O}$ in preference to hexane or toluene to give crystals suitable for X-ray crystallography ${ }^{27}$ (see also below for further examples). Here we demonstrate that Volatile Methyl Siloxanes (VMSs) can be used as replacements for conventional non-polar organic solvents in sustainable chemical processes with neither the need for specialist equipment nor modification of reagents.

\subsection{Properties of volatile methylsiloxanes}

In siloxane nomenclature the terminal $\mathrm{Me}_{3} \mathrm{SiO}$ - group is designated with the abbreviation $\mathbf{M}$ and the - $\left(\mathrm{SiMe}_{2} \mathrm{O}\right)$ - repeating unit as $\mathbf{D} .{ }^{16}$ Hence linear and cyclic species can be referred to by using a representative combination of letters (Table 1). It should be noted that the cyclic $\left(\mathrm{Me}_{2} \mathrm{SiO}\right)_{3}$ is a solid at room temperature and is relatively susceptible to ring-opening reactions, it has not, therefore, been included in this study. Siloxanes bearing alkyl groups other than methyl, and aryl groups are also well known ${ }^{16,20}$ but they generally more expensive, and more viscous and high boiling than the methyl analogues and so they have also been excluded from this study. (Low molecular weight siloxanes containing Si-H or Si-halogen bonds are reactive and so are unsuitable as solvents for many reactions.) The physical properties of siloxanes do bear some resemblance to traditional organic solvents (Table 2), but their dissimilarities were recognised as being significant enough to prompt this investigation. It should be noted that the potential of VMSs as solvents was described in $2000,{ }^{23}$ but little activity on the topic seems to have occurred since then.

Table 1 The structures of six VMSs

\begin{tabular}{|c|c|}
\hline $\begin{array}{cc}\mathrm{Me} & \mathrm{Me} \\
1 & 1 \\
\mathrm{Me}-\mathrm{Si}-\mathrm{O}-\mathrm{Si}-\mathrm{Me} \\
1 \\
\mathrm{Me} & 1 \\
\mathrm{Me}\end{array}$ & \begin{tabular}{ccc}
$\mathrm{Me}$ & $\mathrm{Me}$ & $\mathrm{Me}$ \\
1 & 1 \\
$\mathrm{Me}-\mathrm{Si}-$ & $-\mathrm{O}-\mathrm{Si}-$ & \multicolumn{1}{c}{$-\mathrm{O}-\mathrm{Si}-\mathrm{Me}$} \\
1 & 1 & 1 \\
$\mathrm{Me}$ & $\mathrm{Me}$ & $\mathrm{Me}$
\end{tabular} \\
\hline Hexamethyldisiloxane $\left(\mathbf{M}_{\mathbf{2}}\right)$ & Octamethyltrisiloxane (MDM) \\
\hline $\begin{array}{cccc}\mathrm{Me} & \mathrm{Me} & \mathrm{Me} & \mathrm{Me} \\
\mathrm{I} & 1 & 1 & 1 \\
\mathrm{Me}-\mathrm{Si}-\mathrm{O}-\mathrm{Si}-\mathrm{O} & \mathrm{S} & \mathrm{S}-\mathrm{O}-\mathrm{O}-\mathrm{Si}-\mathrm{Me} \\
1 & 1 & 1 & 1 \\
\mathrm{Me} & \mathrm{Me} & \mathrm{Me} & \mathrm{Me}\end{array}$ & 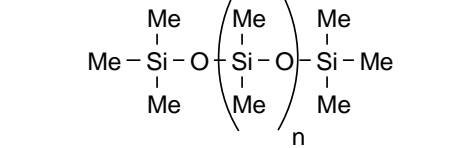 \\
\hline Decamethyltetrasiloxane $\left(\mathbf{M D}_{\mathbf{2}} \mathbf{M}\right)$ & Poly(dimethylsiloxane) (PDMS) \\
\hline 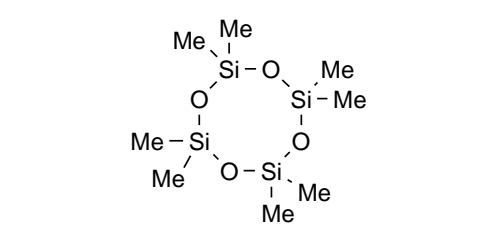 & 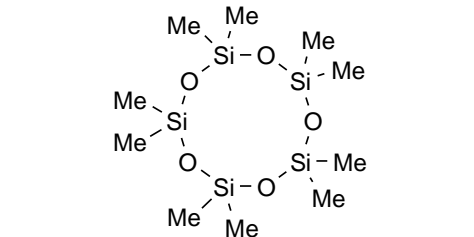 \\
\hline
\end{tabular}

Octamethylcyclotetrasiloxane $\left(\mathbf{D}_{\mathbf{4}}\right) \quad$ Decamethylcyclopentasiloxane $\left(\mathbf{D}_{\mathbf{5}}\right)$ 
Table 2 The physical properties of VMSs and some common solvents (measured at $25^{\circ} \mathrm{C}$ if temperature dependent unless otherwise stated)

\begin{tabular}{|c|c|c|c|c|c|c|c|c|}
\hline Physical properties & $\mathbf{M}_{2}$ & MDM & $\mathbf{D}_{4}$ & $\mathbf{D}_{5}$ & Hexane & $\begin{array}{l}\text { Diethyl } \\
\text { ether }\end{array}$ & Toluene & Ref. \\
\hline Molecular weight /g. $\mathrm{mol}^{-1}$ & 162.38 & 236.53 & 296.62 & 370.77 & 86.18 & 74.12 & 92.14 & \\
\hline Density /g.cm ${ }^{-3}$ & 0.762 & 0.820 & 0.950 & 0.953 & 0.661 & 0.714 & 0.867 & 28,29 \\
\hline Melting point $/{ }^{\circ} \mathrm{C}$ & -67 & -80 & 18 & -44 & -95 & -116 & -95 & 20,29 \\
\hline Boiling point $/{ }^{\circ} \mathrm{C}$ & 100 & 153 & 176 & 210 & 69 & 35 & 111 & 20,29 \\
\hline Vapour pressure $/ \mathrm{kPa}$ & 5.61 & 0.52 & 0.13 & 0.023 & 20.2 & 71.7 & 3.8 & 21,29 \\
\hline F.P. $/{ }^{\circ} \mathrm{C}$ & -9 & 37 & 69 & 77 & -22 & -45 & 4 & $\begin{array}{l}20,29, \\
30\end{array}$ \\
\hline Dynamic viscosity /mPa.s & 0.50 & 0.85 & 2.19 & 3.70 & 0.30 & 0.22 & 0.56 & 22,29 \\
\hline Aq. solubility /mg.L $\mathrm{L}^{-1}$ & 0.93 & 0.034 & 0.056 & 0.017 & 9.8 & 64200 & 519 & 22,29 \\
\hline $\begin{array}{l}\text { Surface tension } / \mathrm{mN} \cdot \mathrm{m}^{-1} \\
\left(20^{\circ} \mathrm{C}\right)\end{array}$ & 15.7 & 16.95 & 17.93 & 18.04 & 18.40 & 17.10 & 28.52 & $\begin{array}{l}31,32, \\
33\end{array}$ \\
\hline
\end{tabular}

\subsection{Health and safety considerations}

The environmental health and safety (EHS) profiles of VMSs can be graphically represented using the concept previously defined by Capello et al. to rank organic solvents (Fig. 1). ${ }^{34}$ In addition to a selection of the solvents scrutinised in the original publication, this work presents an equivalent analysis of seven VMSs. The assessment utilises three categories to define each of the three EHS indicators of health, safety, and environment to create a numerical score for each solvent. Low scores indicate that the solvent is preferred from an EHS perspective. In a deviation from the original method, the parameter previously used to quantify the air hazard category within the environment indicator has been replaced by the photochemical ozone creation potential (POCP) of each solvent. This allows for a fair comparison between all the entries. Therefore the full list of categories that have been used to assess the greenness of VMSs as solvents is as follows. In the safety indicator; release potential, fire or explosion risk, and reaction or decomposition potential. In the health indicator; acute toxicity, chronic toxicity, and irritation. In the environment indicator; persistency, air hazard (POCP), and water hazard.

By this assessment, it is clear that VMSs may be used to reduce the EHS impact of a chemical process and so to make it greener, if all other aspects of the process, such as energy use, remain unchanged. What is also evident is that there is significant variation within the VMSs regarding their EHS profiles. Three of the analysed $\mathrm{VMSs}_{\mathbf{3}} \mathbf{M D}_{\mathbf{3}} \mathbf{M}, \mathbf{D}_{\mathbf{4}}$ and $\mathbf{D}_{\mathbf{5}}$ ) present some health risks of comparable magnitude to some of the traditional organic solvents included in the assessment, although these are less than those of the non-polar solvents for which the VMSs are likely replacements (see below). Whereas $\mathbf{M D}_{\mathbf{3}} \mathbf{M}$ and $\mathbf{D}_{\mathbf{5}}$ are irritants, $\mathbf{D}_{\mathbf{4}}$ is believed to impair fertility ${ }^{35-37}$ and to exhibit estrogenic behaviour in rats and mice (see, for example, refs. 38, 39) The remaining VMSs have no associated health risks according to this particular methodology. Therefore it is recommended that solvent choice between VMSs should be scrutinised with an emphasis on both practical and EHS considerations, just as it should within more traditional solvent classes. Generally the VMSs with greater molecular weights are safer to handle due to their lower vapour pressures and higher flash points. These results can be compared to the conclusions presented in the Pfizer medicinal chemistry solvent 'traffic light' selection guide, ${ }^{2}$ in which solvents are also organised according to their respective EHS profiles. The EHS profiles of VMSs most closely resemble those of solvents deemed to be green in this system. 


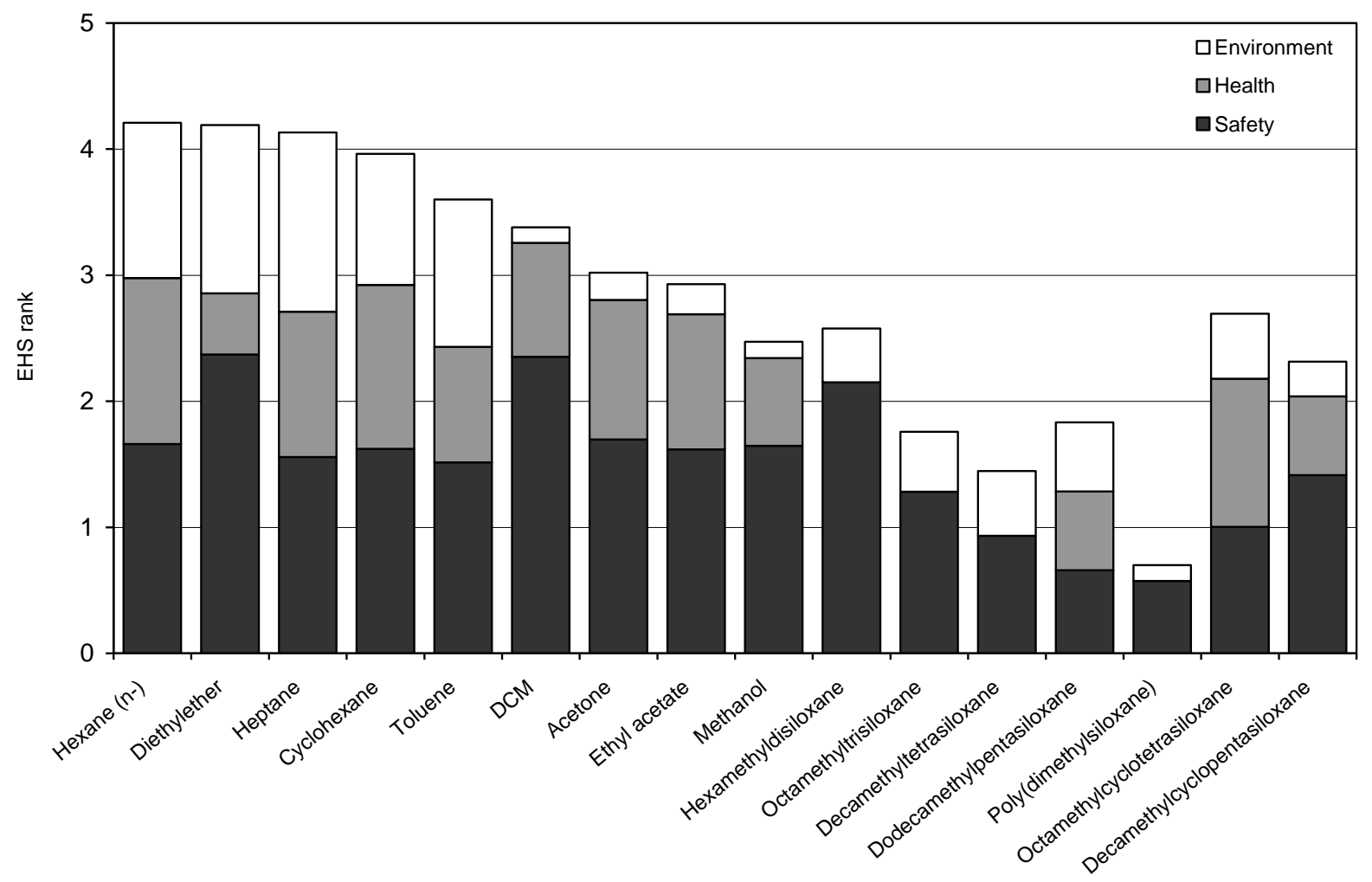

Fig. 1 The EHS profiles for a variety of traditional solvents and VMSs

\subsection{Environmental properties}

Volatile methylsiloxanes already enter the environment in many ways due to their significant uses in household and personal care products, cleaning agents and industrial products. The distribution and fate of VMSs in the air and in aqueous environments has, therefore, been extensively studied, [see, for example, refs. 40-47] and as a result their environmental impacts are widely recognised. ${ }^{37}$ A Canadian study, has for example, concluded that D5 meets some toxicity and persistence criteria but not its bioacculuation criterion ${ }^{48}$ while a recent update of the Equilibrium Criterion Model provides a wide range of physical and envrionmental parameters for D5. ${ }^{49}$ In the UK the cyclic siloxanes have been assessed for persistence, bioaccumulation and toxicity. ${ }^{50-52}$ However, further studies are clearly needed on the bioaccumulative effects of VMSs as not all studies are in agreement (see for example, ref. 40). This current study does not attempt to review in detail the environmental aspects of siloxanes, however, they do need to be borne in mind. Being both hydrophobic and less dense than water, if low molecular weight VMSs enter into an aqueous environment they preferentially form a thin film on the water's surface and rapidly evaporate (Table 3). Experimental data for $\mathbf{D}_{\mathbf{4}}$ and $\mathbf{D}_{5}$ demonstrate that their aquatic half-lives are up to 6 days and 2 days respectively, ${ }^{53}$ which compares very favourably with commonly used organic solvents. The hazard posed by VMSs to aquatic environments has been judged to be minimal, validated by German Wassergefährdungsklassen (WGK) water hazard classifications. ${ }^{21}$ The high molecular weight PDMS oligomers lack sufficient volatility to be directly transported into the atmosphere. These compounds tend to associate themselves with the sludge deposits of water treatment plants or in soil. Abiotic hydrolysis is the fastest known decomposition pathway for PDMS, from which volatile silanols are formed. ${ }^{54}$ Dimethylsilanediol, $\mathrm{Me}{ }_{2} \mathrm{Si}(\mathrm{OH})_{2}$, and trimethylsilanol, $\mathrm{Me}_{3} \mathrm{SiOH}$, are the eventual products upon depolymerisation of the siloxane backbone. 
Table 3 The environmental characteristics of VMSs and some traditional solvents. Theoretical values are presented in parentheses.

\begin{tabular}{|c|c|c|c|c|c|c|c|c|}
\hline Environmental properties & $\mathbf{M}_{2}$ & MDM & $\mathbf{D}_{4}$ & $\mathbf{D}_{5}$ & Hexane & $\begin{array}{l}\text { Diethyl } \\
\text { ether }\end{array}$ & Toluene & Refs. \\
\hline Aquatic $\mathrm{t}_{1 / 2} /$ days & $(0.28)$ & $(0.34)$ & $1-6$ & $1-2$ & 7 & 30 & 6 & $\begin{array}{l}21,53, \\
55\end{array}$ \\
\hline $\log K_{\text {Ow }}$ & 4.2 & 4.8 & $\begin{array}{l}6.98 \pm \\
0.13\end{array}$ & $\begin{array}{l}8.07 \pm \\
0.22\end{array}$ & 4.0 & 0.89 & 2.7 & $\begin{array}{l}20,29, \\
56\end{array}$ \\
\hline WGK & 1 & 1 & 1 & 1 & 3 & 1 & 2 & 21,34 \\
\hline РОCP & 0 & 0 & 0 & 0 & 48 & 47 & 64 & 21,57 \\
\hline
\end{tabular}

Once in the atmosphere the low molecular weight VMSs photodegrade under the action of hydroxyl radicals to form silanols. Therefore, the environmental consequences of VMS contamination are dictated by the properties of their silanol degradation products. The rate at which $\mathrm{Me}_{3} \mathrm{SiOH}$ photolytically decomposes has been experimentally determined to be greater than that observed for a selection of siloxanes. ${ }^{58}$ Exclusion of VMSs from VOC regulations in the United States of America is justified by the benign nature of their ultimate photodegradation products, namely carbon dioxide, silica, and water (Scheme 1). ${ }^{53,59}$ Siloxanes have a tendency to terminate free radical reactions, rather than acting as a radical source and do not facilitate low level ozone formation. ${ }^{53}$ Hence VMSs have a POCP rating of zero. $^{21}$

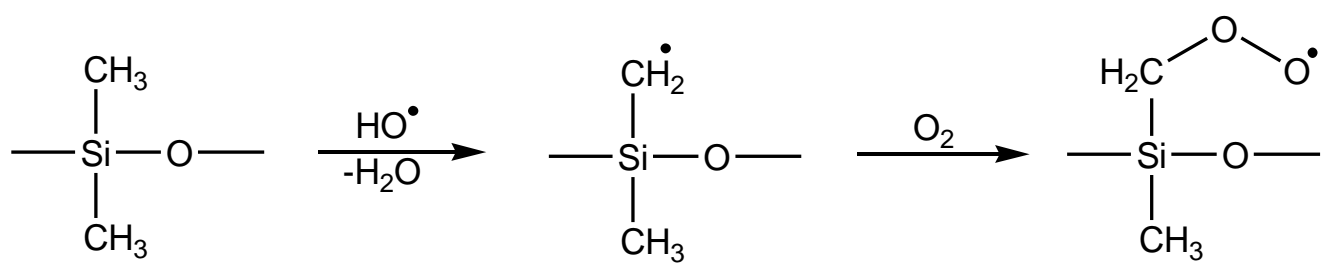

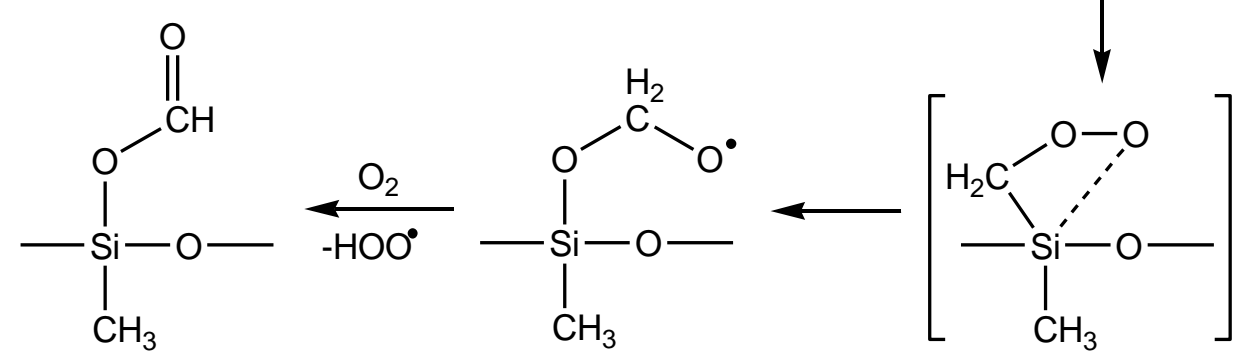

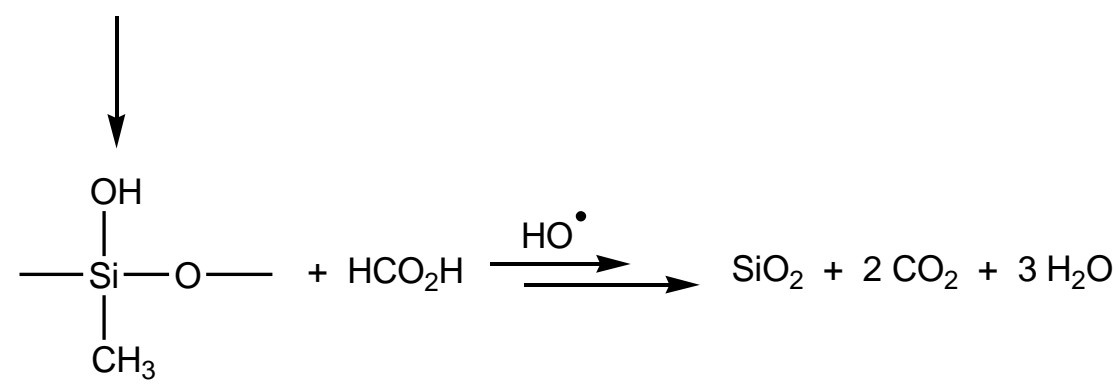

Scheme 1 The degradation of a generic VMS fragment. ${ }^{53}$ 
Silanol species may alternatively be removed from the atmosphere by wet deposition and returned to an aqueous environment. Although $\mathrm{Me}_{3} \mathrm{SiOH}$ is volatile, $\mathrm{Me}_{2} \mathrm{Si}(\mathrm{OH})_{2}$ may only very slowly return to the atmosphere, such is its affinity towards water. The decomposition of aqueous $\mathrm{Me}_{2} \mathrm{Si}(\mathrm{OH})_{2}$ has been shown to occur via an oxidative demethylation mechanism. ${ }^{60}$ It should also be acknowledged that incineration is likely to be an option for VMS disposal after both industrial use and the retrieval of contaminated sludge from waste water treatments. The combustion products of VMSs, $\mathrm{CO}_{2}, \mathrm{H}_{2} \mathrm{O}$ and $\mathrm{SiO}_{2}$, are the same as those observed for their photodegradation, and are significantly less toxic than those observed for many other organic compounds. ${ }^{21}$

\section{Results and discussion}

\subsection{Polarity measurements}

Polarity has traditionally been one of the primary methods of describing the physical properties of solvents. ${ }^{61}$ It includes all possible solvent-solute interactions except those that give rise to a chemical transformation. We have chosen the Kamlet-Taft system for describing solvent polarity of hydrogen bond acidity ( $\boldsymbol{\alpha})$ and basicity ( $\boldsymbol{\beta}$ ) and dipolarity/polarisability $\left(\boldsymbol{\pi}^{*}\right) .^{62-65}$ These were derived from the uv-vis spectra of three dyes, namely Nile red, $p$ nitroaniline, and $N, N$-diethyl-p-nitroaniline (Table 4). Nile red was used as an alternative to the more commonly used Reichardt's dye because poor solubility of the latter in the VMSs prevented its use. With near-zero values for all three of these parameters, the VMSs can be said to be similar to alkanes, not ethers as might be expected from their chemical structures. Hence VMSs are typified by their low polarity, hydrophobic nature and surprisingly low viscosity, ${ }^{66,67}$ and are likely to be good replacements for alkanes in any polarity dependent process. To this end, $\mathbf{M}_{\mathbf{2}}$ has previously been applied in the purification of metal phosphide complexes, either as a recrystallisation solvent or to otherwise wash out impurities from crude products. ${ }^{68-71}$

Table 4 Kamlet-Taft polarity parameters for various organic solvents and VMSs

\begin{tabular}{llllll}
\hline Class & Compound & $\boldsymbol{\alpha}$ & $\boldsymbol{\beta}$ & $\boldsymbol{\pi}^{*}$ & Ref. \\
\hline Linear siloxane & $\mathbf{M}_{\mathbf{2}}$ & $0^{\S}$ & 0.06 & 0.01 & This work. \\
Linear siloxane & $\mathbf{M D M}$ & $0^{\S}$ & 0.11 & 0.02 & This work. \\
Linear siloxane & PDMS $\left(2000{\left.\mathrm{~g} . \mathrm{mol}^{-1}\right)}^{-1}\right.$ & $0^{\S}$ & 0.19 & 0.11 & This work. \\
Cyclic siloxane & $\mathbf{D}_{\mathbf{4}}$ & $0^{\S}$ & 0.12 & 0.04 & This work. \\
Cyclic siloxane & $\mathbf{D}_{\mathbf{5}}$ & $0^{\S}$ & 0.14 & 0.07 & This work. \\
Alcohol & Methanol & 0.56 & 0.63 & 0.72 & 62,72 \\
Alkane & $n$-Hexane & $0^{\S}$ & 0.04 & $0^{\S}$ & 62,72 \\
Ester & Ethyl acetate & $0^{\S}$ & 0.50 & 0.54 & 62,72 \\
Ether & Diethyl ether & $0^{\S}$ & 0.52 & 0.28 & 62,72 \\
Ketone & Acetone & $0^{\S}$ & 0.54 & 0.70 & 72,73 \\
\hline
\end{tabular}

${ }_{\S}^{\S}$ Negative values set to zero.

\subsection{Solubilities of volatile methylsiloxanes}

The solubility of numerous organic solvents in VMSs was tested to complement the polarity measurements. In cases where 1:1 (v:v) mixtures were not miscible, ${ }^{1} \mathrm{H}$ NMR spectroscopy was used to derive the solubility of both the organic solvent in the VMS and vice-versa. Many common laboratory solvents are soluble with equal volumes of the VMSs examined (Tables 5 and 6). Exceptions include dimethylformamide (DMF) and pyridine in all cases, with acetic 
acid, dimethyl carbonate, ethanol and methanol preferentially forming liquid-liquid biphasic systems with the higher molecular weight VMSs only. The solubility of gases in VMSs is comparable to that in organic solvents, but a greater uptake rate has been reported, ${ }^{74}$ suggesting that VMSs may be good alternative solvents for reactions of these (Table 7).

Table 5 The room temperature solubility (v/v) of organic solvents in VMSs from 1:1 binary mixtures

\begin{tabular}{llllll}
\hline Solute & $\mathbf{M}_{\mathbf{2}}$ & $\mathbf{M D}_{\mathbf{3}} \mathbf{M}$ & $\begin{array}{l}\text { PDMS } \\
\left(2000 \mathrm{~g} \cdot \mathrm{mol}^{-1}\right)\end{array}$ & $\mathbf{D}_{\mathbf{4}}$ & $\mathbf{D}_{\mathbf{5}}$ \\
\hline Acetic acid & $\geq 1.00$ & 0.146 & 0.096 & $\geq 1.00$ & 0.182 \\
Dichloromethane & $\geq 1.00$ & $\geq 1.00$ & $\geq 1.00$ & $\geq 1.00$ & $\geq 1.00$ \\
Diethyl ether & $\geq 1.00$ & $\geq 1.00$ & $\geq 1.00$ & $\geq 1.00$ & $\geq 1.00$ \\
Dimethyl carbonate & $\geq 1.00$ & $\geq 1.00$ & 0.292 & $\geq 1.00$ & $\geq 1.00$ \\
Dimethylformamide & 0.008 & 0.015 & 0.023 & 0.032 & 0.026 \\
Ethanol & $\geq 1.00$ & $\geq 1.00$ & 0.175 & $\geq 1.00$ & $\geq 1.00$ \\
Ethyl acetate & $\geq 1.00$ & $\geq 1.00$ & $\geq 1.00$ & $\geq 1.00$ & $\geq 1.00$ \\
$n$-Hexane & $\geq 1.00$ & $\geq 1.00$ & $\geq 1.00$ & $\geq 1.00$ & $\geq 1.00$ \\
Methanol & $\geq 1.00$ & 0.078 & 0.026 & $\geq 1.00$ & 0.173 \\
Methyl ethyl ketone & $\geq 1.00$ & $\geq 1.00$ & $\geq 1.00$ & $\geq 1.00$ & $\geq 1.00$ \\
Pyridine & 0.132 & 0.209 & 0.169 & 0.393 & 0.294 \\
Toluene & $\geq 1.00$ & $\geq 1.00$ & $\geq 1.00$ & $\geq 1.00$ & $\geq 1.00$ \\
\hline
\end{tabular}

Table 6 The room temperature solubility (v/v) of VMSs in organic solvents from 1:1 binary mixtures

\begin{tabular}{llllll}
\hline Solvent & $\mathbf{M}_{\mathbf{2}}$ & $\mathbf{M D}_{\mathbf{3}} \mathbf{M}$ & $\begin{array}{l}\text { PDMS } \\
\left(2000 \mathrm{~g} \cdot \mathrm{mol}^{-1}\right)\end{array}$ & $\mathbf{D}_{\mathbf{4}}$ & $\mathbf{D}_{\mathbf{5}}$ \\
\hline Acetic acid & $\geq 1.00$ & 0.195 & 0.000 & $\geq 1.00$ & 0.253 \\
Dichloromethane & $\geq 1.00$ & $\geq 1.00$ & $\geq 1.00$ & $\geq 1.00$ & $\geq 1.00$ \\
Diethyl ether & $\geq 1.00$ & $\geq 1.00$ & $\geq 1.00$ & $\geq 1.00$ & $\geq 1.00$ \\
Dimethyl carbonate & $\geq 1.00$ & $\geq 1.00$ & 0.052 & $\geq 1.00$ & $\geq 1.00$ \\
DMF & 0.775 & 0.079 & 0.000 & 0.155 & 0.076 \\
Ethanol & $\geq 1.00$ & $\geq 1.00$ & 0.249 & $\geq 1.00$ & $\geq 1.00$ \\
Ethyl acetate & $\geq 1.00$ & $\geq 1.00$ & $\geq 1.00$ & $\geq 1.00$ & $\geq 1.00$ \\
$n$-Hexane & $\geq 1.00$ & $\geq 1.00$ & $\geq 1.00$ & $\geq 1.00$ & $\geq 1.00$ \\
Methanol & $\geq 1.00$ & 0.329 & 0.017 & $\geq 1.00$ & 0.631 \\
Methyl ethyl ketone & $\geq 1.00$ & $\geq 1.00$ & $\geq 1.00$ & $\geq 1.00$ & $\geq 1.00$ \\
Pyridine & 0.987 & 0.092 & 0.011 & 0.282 & 0.176 \\
Toluene & $\geq 1.00$ & $\geq 1.00$ & $\geq 1.00$ & $\geq 1.00$ & $\geq 1.00$ \\
\hline
\end{tabular}


Table 7 Gas solubilities in $\mathbf{D 4}$ and various organic solvents

\begin{tabular}{llllll}
\hline Gas & \multicolumn{4}{l}{ Gas solubility $\times 10^{3}(\mathrm{w} / \mathrm{w})$ in the given solvents at atmospheric pressure } & Ref. \\
& $\mathbf{D}_{4}$ & $n$-Hexane & Diethyl ether & Toluene & \\
\hline $\mathrm{H}_{2}$ & 0.07 at $30{ }^{\circ} \mathrm{C}$ & 0.016 at $21{ }^{\circ} \mathrm{C}$ & 0.016 at $25{ }^{\circ} \mathrm{C}$ & 0.007 at $25^{\circ} \mathrm{C}$ & $74-77$ \\
$\mathrm{O}_{2}$ & 0.46 at $25^{\circ} \mathrm{C}$ & 0.750 at $20{ }^{\circ} \mathrm{C}$ & 0.843 at $25{ }^{\circ} \mathrm{C}$ & 0.321 at $25^{\circ} \mathrm{C}$ & $75-77$ \\
$\mathrm{CO}$ & 0.308 at $25{ }^{\circ} \mathrm{C}$ & 0.566 at $20^{\circ} \mathrm{C}$ & 0.640 at $25{ }^{\circ} \mathrm{C}$ & 0.244 at $25^{\circ} \mathrm{C}$ & $75-77$ \\
$\mathrm{CO}_{2}$ & 3.98 at $30^{\circ} \mathrm{C}$ & 6.22 at $21{ }^{\circ} \mathrm{C}$ & 16.3 at $25{ }^{\circ} \mathrm{C}$ & 5.07 at $25^{\circ} \mathrm{C}$ & $75-77$ \\
\hline
\end{tabular}

\subsection{Applications in synthesis}

A number of organic and inorganic transformations were attempted in various VMSs to assess their potential as reaction solvents (Scheme 2). We are not here attempting to provide a comprehensive list of all reactions that could be attempted in VMSs nor to complete systematic investigations of all potential solvent effects on these reactions, but rather to give an indication of the range of possibilities available. There are several VMSs that could be used for these reactions. We have selected $\mathbf{M}_{2}$ as our prototypical VMS and used a variety of different VMSs in each of the reactions, again to exemplify the range of possibilities available. We did investigate reactions that have previously been used to characterize solvent behaviours, ${ }^{61}$ before going on to study other widely used synthetic procedures. No siloxane specific effects were observed within this set of reactions; while some reactions gave isolated yields exceeding those obtained using non-polar organic solvents, many gave comparable yields. For completeness, reactions that were attempted, but gave significantly poorer results than in non-polar organic solvents are recorded in the Electronic Supplementary Information.

Reaction $1 \longrightarrow \mathrm{NEt}_{3}+\mathrm{Mel} \longrightarrow \mathrm{Et}_{3} \mathrm{MeNI}$

Reaction 2

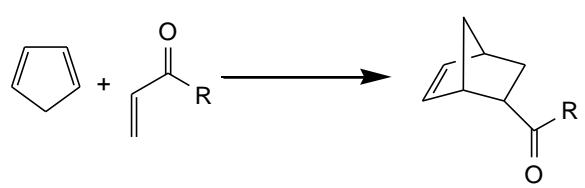

(2)

Reaction 3

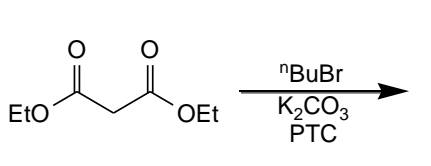<smiles>CCCCC(C(=O)OCC)C(=O)OCC</smiles>

(3)

Reaction 4<smiles>CCOC(=O)C(O)c1ccccc1</smiles><smiles>CCOC(=O)C(=O)c1cccc(C(C)C(C)C)c1</smiles>

(4)

Reaction 5

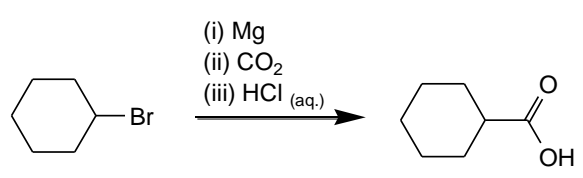

(5)

Scheme 2 Five examples of organic transformations conducted in a VMS solvent. Reaction 1; exhaustive amine alkylation. Reaction 2; Diels-Alder cycloaddition where the dienophile is either methyl acrylate $(\mathrm{R}=\mathrm{OMe})$ or acrolein $(\mathrm{R}=\mathrm{H})$. Reaction 3; enolate alkylation where PTC = phase transfer catalyst. Reaction 4; alcohol 
oxidation where PTC $=$ phase transfer catalyst. Reaction 5; Grignard reaction and subsequent carboxylation.

Amine alkylation. In parallel with a rare literature example of VMSs being used to facilitate synthetic chemistry, ${ }^{78}$ the alkylation of triethylamine with iodomethane was conducted in $\mathbf{M}_{\mathbf{2}}$ and $\mathbf{D}_{\mathbf{4}}$ (Scheme 3, Reaction 1) and compared with a traditional non-polar solvent, hexane, and a more polar one, THF. The ammonium salt product precipitates cleanly from the VMS solution and is isolated by filtration, without need for further purification beyond removal of the volatiles. The effects of solvents upon the rates of amine alkylations are well understood, the reaction being favoured by polar, nonhydrogen bonding solvents. ${ }^{61,79}$ The rate of alkylation in both $\mathrm{M}_{2}$ and $\mathrm{D}_{4}$, although faster than in $n$-hexane, is slow compared to that observed in tetrahydrofuran, again indicating their low polarities.

Table 8 Isolated yields for the reaction between triethylamine and methyl iodide at room temperature.

\begin{tabular}{cccc}
\hline \hline Experiment & Solvent & Duration & Yield /\% \\
\hline \hline 1 & & $10 \mathrm{~min}$ & 16 \\
2 & & $30 \mathrm{~min}$ & 32 \\
3 & $\mathbf{M}_{\mathbf{2}}$ & $24 \mathrm{~h}$ & 100 \\
4 & & $24 \mathrm{~h}$ & 100 \\
5 & & $24 \mathrm{~h}$ & 100 \\
1 & & $24 \mathrm{~h}$ & 97 \\
2 & $\mathbf{D}_{\mathbf{4}}$ & $24 \mathrm{~h}$ & 92 \\
3 & & $24 \mathrm{~h}$ & 95 \\
\hline 1 & & $24 \mathrm{~h}$ & 76 \\
2 & & $24 \mathrm{~h}$ & 77 \\
3 & $n-H e x a n e$ & $24 \mathrm{~h}$ & 73 \\
4 & & $65 \mathrm{~h}$ & 97 \\
1 & & $10 \mathrm{~min}$ & 88 \\
2 & & $10 \mathrm{~min}$ & 92 \\
3 & THF & $10 \mathrm{~min}$ & 92 \\
\hline
\end{tabular}

Diels-Alder cycloaddition. The effects of solvents upon the rates and selectivities of Diels-Alder Cycloadditions are also well understood. ${ }^{61}$ Hence, the reactions between cyclopentadiene and either methyl acrylate or acrolein were studied in a variety of VMSs and organic solvents (Scheme 3, Reaction 2). The rates of the reactions leading to the endo- adducts are accelerated by greater polarity of the solvent and by hydrogen bonding to the carbonyl group of the dienophile, whereas reactions to the exo- adduct are less affected by the solvent. This, in turn, leads to a greater selectivity to the endo- adducts in polar, hydrogen bond donor solvents. The VMSs gave selectivities that were remarkably similar to each other, and to that observed for the hydrocarbon solvents but lower than those obtained in ethers and ketones (Table 9). This again confirms that the VMSs should be considered to be non-polar, non-hydrogen bond donor solvents. ${ }^{80}$ 
Table 9 Endo/exo selectivity ratios observed for the cycloaddition reaction between cyclopentadiene and two dienophiles at $25^{\circ} \mathrm{C}$

\begin{tabular}{|c|c|c|c|}
\hline Solvent & endo/exo $o_{\text {acrolein }}$ & endo/exo methyl acrylate & Ref. \\
\hline Acetone & 3.6 & 3.4 & 81 \\
\hline Diethyl ether & $\mathrm{n} / \mathrm{a}$ & 2.9 & 81 \\
\hline PDMS $\left(\mathrm{RMM}=2000 \mathrm{~g} \cdot \mathrm{mol}^{-1}\right)$ & 3.0 & 2.6 & This work. \\
\hline $\mathbf{M}_{2}$ & 3.0 & 2.6 & This work. \\
\hline MDM & 2.9 & 2.6 & This work. \\
\hline $\mathbf{D}_{4}$ & 2.9 & 2.6 & This work. \\
\hline $\mathbf{D}_{5}$ & 2.8 & 2.6 & This work. \\
\hline$n$-Hexane & 2.8 & 2.5 & 81 \\
\hline Toluene & 2.4 & 2.7 & 81 \\
\hline
\end{tabular}

Phase Transfer Catalysis and Emulsion Formation. Phase-transfer catalysis (PTC) is a well established technique ${ }^{82}$ that has many commercial applications. It has recently been recognised to have the potential to give rise to green synthetic routes. ${ }^{83}$ Its advantages for commercial application (increased rates of reaction and product specificity, low energy requirements, use of inexpensive catalysts and bases) are also advantages for sustainable chemistry. The immiscibility of VMSs with water leads to these being candidate solvents for the non-polar phase in PTC. Their antifoaming properties ${ }^{84}$ are also likely to be an advantage in this application.

It was noticed that when carrying out various reactions using the VMS solvents, with the exception of PDMS, separation from water usually occurred faster than with other organic solvents. It is unclear why this should be the case but it may be due to the VMSs' low surface tension, lower polarity or larger molecular size and it is consistent with the well known use of siloxanes as industrial defoaming agents. ${ }^{84}$ A brief qualitative study comparing solvents' emulsion behaviour was performed using M2 and toluene (as this was used some of the synthesis reactions) to ascertain whether there are any significant differences between siloxanes and hydrocarbons. An ultrasonic bath was used to emulsify biphasic mixtures of water and solvent and the rate at which the emulsion cleared into two separate solvent layers was observed. For mixtures containing $5 \mathrm{ml}$ each of toluene/water and M2/water the time taken for the emulsions to clear was ca. $24 \mathrm{~h}$ and $2 \mathrm{~h}$ respectively. On adding $25 \mathrm{mg} \mathrm{Bu}{ }_{4}{ }_{\mathrm{NBr}}$ as a phase transfer catalyst to each solution the emulsion clearance times were increased significantly to $c a .60 \mathrm{~h}$ and $16 \mathrm{~h}$ respectively. Thus, while this is a crude and qualitative study, it is clear that the rate of separation with M2 is greater than that of toluene. While this type of behaviour is difficult to quantify, the clear difference indicates that VMSs are less likely to form and maintain emulsions in general. This may be a useful feature to consider for large scale extractions and biphasic reactions where emulsion formation can be problematic.

Tetraalkylammonium salts are the most commonly used phase transfer catalysts. ${ }^{82}$ Hence, the oxidation of ethyl mandelate to ethyl-oxo-phenylacetate by calcium hypochlorite in the presence of a tetraalkylammonium halide phase transfer catalyst was attempted (Scheme 3, Reaction 4). Separation of the product in the VMS phase was easily achieved and the product was then isolated by removal of the solvent. The oxidising agent and by-products remained in the aqueous phase. The reaction can be performed in $\mathbf{M}_{2}$ to give an improved yield (53 and 60\% for two repeats) over the reaction in cyclohexane (40 and $44 \%$ for two reactions) although in both cases the product was heavily contaminated with starting material, about 53 and $42 \%$ respectively for cyclohexane and $\mathbf{M}_{2}$ solvents respectively. Hence, for this reaction the VMS can be used as a replacement solvent for with a slightly improved yield. 
Crown ethers are also widely used to facilitate phase transfer in aqueous-organic biphasic systems. ${ }^{82}$ Hence, the reaction between diethylmalonate and $n$-butyl bromide was performed in an aqueous- $\mathbf{M}_{2}$ biphasic system in the presence of potassium carbonate and 18-crown-6 (Scheme 3, Reaction 3). The yields were similar to those for the same reaction in cyclohexane (Table 10). Elevated temperatures were necessary to achieve the required phase distribution of the catalyst during the reaction. Upon cooling the low concentration of the phase transfer catalyst in the $\mathbf{M}_{2}$ layer, together with the hydropobicity of $\mathbf{M}_{2}$, led to minimal washing being required for the removal of the phase transfer catalyst from the non-polar VMS phase.

Table 10 Isolated yields for the reaction between $n$-butyl bromide and diethyl malonate after $4 \mathrm{~h}$.

\begin{tabular}{cccc}
\hline \hline Experiment & Solvent & Temperature $/{ }^{\circ} \mathrm{C}$ & Yield $/ \%$ \\
\hline \hline 1 & $\mathbf{M}_{\mathbf{2}}$ & 90 & 86 \\
2 & $\mathbf{D}_{\mathbf{4}}$ & 90 & 88 \\
\hline 1 & & & 80 \\
2 & Cyclohexane & 90 & 79 \\
\hline 1 & & & 83 \\
2 & & & 82 \\
\hline
\end{tabular}

As they contain no double bonds and are generally chemically inert they should not undergo reduction themselves. Hence, two aqueous biphasic sodium borohydride reductions, of (1) hexanal and (2) cyclohexanone were also performed with both traditional organic solvents and siloxanes, using tetrabutylammonium bromide as the phase transfer catalyst. The yields using each solvent are presented in Table 11.

Table 11 Biphasic sodium borohydride reduction reactions performed in VMSs and organic solvents

\begin{tabular}{|c|c|c|c|}
\hline Reaction & Solvent & Yield /\% & Conversion/\% \\
\hline 1-hexanal - 1-hexanol & $\begin{array}{c}\mathrm{M}_{2} \\
\text { Hexane } \\
\mathrm{CH}_{2} \mathrm{Cl}_{2} \\
\text { PDMS }\end{array}$ & $\begin{array}{c}78.8 \\
76.8 \\
68.5 \\
\mathrm{~b}\end{array}$ & $\begin{array}{l}>99 \\
>99 \\
>99 \\
>99\end{array}$ \\
\hline cyclohexanone - cyclohexanol & $\begin{array}{c}\text { Toluene } \\
\text { MDM } \\
\text { Pentane }\end{array}$ & $\begin{array}{c}43.4 \\
46.8 \\
\text { b }\end{array}$ & $\begin{array}{l}>99 \\
>99 \\
>99\end{array}$ \\
\hline
\end{tabular}

b: isolated yield unavailable

The biphasic reduction of 1-hexanal to 1-hexanol was carried out in M2 and PDMS for comparison with hexane, and $\mathrm{CH}_{2} \mathrm{Cl}_{2}$. Monitoring by ${ }^{1} \mathrm{H}-\mathrm{NMR}$ spectroscopy showed the loss of the aldehyde proton in the 9.5-10.0 ppm region and that reaction in all the solvents was complete in $20 \mathrm{~min}$. It is possible that some product was being lost during the solvent removal step and, as PDMS is unsuitable for removal by evaporation, in this case the product was removed by distillation. Even after distillation, some PDMS persisted in the product and an accurate yield was difficult to determine, although it was clear from the ${ }^{1} \mathrm{H}$ NMR spectrum that the reaction had gone to completion. It was also noticed that removal of the PTC seemed to be easier from the siloxanes than from the more polar $\mathrm{CH}_{2} \mathrm{Cl}_{2}$, possibly due to the more polar solvet solvating the PTC better. The reduction of cyclohexanone to cyclohexanol was carried out in a similar way with in situ ${ }^{1} \mathrm{H}-\mathrm{NMR}$ spectroscopy indicating complete conversion to cyclohexanol in all solvents. Again all of the reactions were completed in a short period of time at room temperature. The moderate isolated yields of product from this reaction may be due to the slight solubility of the product in water leading to losses during the work- 
up procedure. From these results it can be seen that the reduction of carbonyl functional groups can be achieved in both traditional solvents and in siloxanes in this biphasic system and that the PTC is active in all cases. Despite the monitoring of the reactions showing that they had gone to completion, difficulties in separating the solvents from the products led to a reduction in isolated yields.

$N$-functionalisation of phthalimide Phthalimide derivatives have many applications in chemistry ${ }^{85}$ and so their syntheses in both organic solvents and siloxanes were attempted. The $N$-functionalisation of imides is generally performed by the reaction of the imide with an alkyl halide in the presence of a base such as $\mathrm{NaH}, \mathrm{BuLi}$ or $\mathrm{KOH}$, using solvents such as DMSO, DMF, THF, acetone and xylene and the use of a PTC has also successfully been used to perform a number of $N$-alkylations of imides. ${ }^{86}$ The $N$-benzylation of phthalimide was attempted in $\mathrm{D} 4$, hexane and $\mathrm{CH}_{2} \mathrm{Cl}_{2}$ using TBAB as the catalyst and at the reflux temperature of each solvent for $3 \mathrm{~h}$. In this case the high yield obtained from the reaction performed in D4 (Table 12) is likely to be due to the relatively high boiling point of D4 $\left(176^{\circ} \mathrm{C}\right.$ compared to 69 and $40^{\circ} \mathrm{C}$ for hexane and $\mathrm{CH}_{2} \mathrm{Cl}_{2}$ respectively).

Table 12 N-functionalisation of phthalimide

\begin{tabular}{ccc}
\hline \hline Alkylating agent & Solvent & Yield /\% \\
\hline \multirow{3}{*}{ Benzyl chloride } & $\mathrm{D}_{4}$ & 89 \\
& $\mathrm{Hexane}$ & 22 \\
& $\mathrm{CH}_{2} \mathrm{Cl}_{2}$ & 14 \\
\hline \multirow{2}{*}{ isobutyl bromide } & $\mathrm{MDM}$ & 51 \\
& Toluene & 17 \\
\hline
\end{tabular}

Performing this reaction in a VMS may also lead to improvements from a work-up point of view: On completion of the reactions, water was added to the reaction flask to dissolve the base, PTC and any remaining phthalimide. The reaction mixture was allowed to cool and in the cases of the VMSs and the hexane as solvents the product crystallised from solution yielding a high purity product. The product remained in the organic phase of reaction carried out in $\mathrm{CH}_{2} \mathrm{Cl}_{2}$, thus requiring separation of the organics and rotary evaporation to remove the solvent off.

The N-alkylation of phthalimide with isobutyl bromide was performed in MDM and in toluene (Table 12). The reaction in MDM gave the better yield of the two and it is again likely that the higher boiling point assisted the reaction progress. However, although monitoring of the reaction by tlc showed the complete consumption of isobutylbromide the yields are low. In this case the relatively low boiling point of the bromide may have lead to losses by evaporation. Despite this the reactions in the VMS biphasic systems outperformed their organic solvent equivalents, and demonstrate the suitability of VMSs for this type of reaction. An advantage here is that solubility in VMSs is not key to the success of the reaction, with neither phthalimide nor the reaction products showing significant solubility in VMSs. The ease of product separation in the case of VMSs is an advantage over some other solvents: polar solvents such as DMF and alcoholic solvents may require further work-up steps as product and any remaining starting material remain in the same phase.

Grignard reaction. A Grignard reaction was attempted to assess the ability of VMSs to facilitate organometallic chemistry (Scheme 3, Reaction 5). This was selected in preference to an alkyllithium reagent such as BuLi as this is well known to lead to ring-opening reactions of siloxanes. ${ }^{87}$ For this reason the reaction was carried out only in $\mathbf{M}_{\mathbf{2}}$. Yields for the various reactions are shown in Table 13. Reactions in neat $\mathbf{M}_{2}$ yielded no product indicating that, in spite of the presence of lone pair-bearing oxygen atoms, the siloxanes do not act as even moderate bases. However, using a 
siloxane/THF mix of solvents allows a yield as good as, if not better than the conventional ether solvents. Thus, again a siloxane may be used at least as a partial substitute for a traditional solvent.

Table 13 Isolated yields for the carboxylation of bromocyclohexane via a Grignard reaction

\begin{tabular}{ccc}
\hline \hline Solvent & Repeats & Yield /\% \\
\hline $\mathbf{M}_{\mathbf{2}}$ & 1 & 0 \\
\hline $\mathbf{M}_{\mathbf{2}}: \mathrm{THF}(4.5: 0.5)$ & 1 & 0 \\
\hline $\mathbf{M}_{\mathbf{2}}: \mathrm{THF}(4: 1)$ & 1 & 46 \\
& 2 & 49 \\
\hline THF & 1 & 28 \\
& 2 & 30 \\
\hline Diethyl ether & 1 & 41 \\
& 2 & 43 \\
\hline
\end{tabular}

Hydrogenation reactions Several catalytic hydrogenation reactions were also performed in VMSs to examine their suitability for this class of reaction (Table 14). Two solvents, $\mathrm{M}_{2}$ and methanol were chosen, $\mathrm{M}_{2}$ being the only VMS that allows easy removal by rotary evaporation. Details of the compounds used and reaction conditions are detailed in Table 13. For the nitrobenzene and cycloheptene 5\% Pd on carbon was the catalyst. Nitrobenzene is highly polar and exhibited only moderate solubility in $\mathrm{M}_{2}$ and a second phase containing nitrobenzene was visible at the start of the reaction. However, when complete the reaction mixture was homogenous and the reaction had occurred as well in M2 as it had in methanol. Analysis of the product from the reaction in $\mathrm{MeOH}$ by ${ }^{1} \mathrm{H}-\mathrm{NMR}$ spectroscopy indicated low levels $(0.6 \%)$ of $\mathrm{N}$-methylaniline, indicated by the $\mathrm{N}-\mathrm{CH}_{3}$ proton peak at $2.87 \mathrm{ppm}$ but this was not seen in the product obtained when using M2 as solvent.

Table 14 Pd-catalysed hydrogenation reactions

\begin{tabular}{ccccc}
\hline \multirow{2}{*}{ Reaction } & Solvent & Yield /\% & Conversion/\% & \multirow{2}{*}{ time } \\
\hline \hline \multirow{2}{*}{ Cycloheptene to cycloheptane } & $\mathrm{M}_{2}$ & $a$ & $>99$ & $90 \mathrm{~min}$ \\
& Methanol & $a$ & $>99$ & $90 \mathrm{~min}$ \\
\hline \multirow{2}{*}{ Nitrobenzene to aniline } & $\mathrm{M}_{2}$ & 79 & $>99$ & $140 \mathrm{~min}$ \\
& Methanol & 71 & $>99$ & $140 \mathrm{~min}$ \\
\hline \multirow{2}{*}{ Benzaldehyde to benzyl alcohol } & $\mathrm{M}_{2}$ & 74 & $>99$ & $19 \mathrm{~h}^{\mathrm{c}}$ \\
& Methanol & 64 & $>99$ & $19 \mathrm{~h}^{\mathrm{c}}$ \\
\hline
\end{tabular}

$a-$ yields not measured due to problems in separating the product from the solvent.

$b$ - conversion determined by 'H-NMR spectroscopy.

$c$ - hydrogen balloons deflated over night and were refilled the following morning and the reaction continued.

Cycloheptene was subjected to hydrogenation using a similar technique and again the rate of reaction in both M2 and methanol was similar. Complete conversion to cycloheptane was achieved by both solvents after 90 minutes with no observable byproducts. To examine effectiveness of $\mathbf{M}_{2}$ as a solvent for use with other catalysts the benzaldehyde was hydrogenated using platinum dioxide (Adam's catalyst). A procedure from the literature was 
followed where, along with Adam's catalyst, triethylamine was used to promote the hydrogenation. ${ }^{87}$ Carbonyl groups are often more difficult to reduce than an olefins and a longer reaction time was required for this reaction. Analysis after 1 hour indicated little conversion. Reactions were allowed to continue overnight and after $19 \mathrm{~h}$ both reactions were complete. A filtration through a silica plug was performed to remove both catalyst and promoter and the solvent was then removed to give the product.

From the isolated yields obtained for each reaction it is clear the VMS solvent M2 is a potentially useful solvent in which to perform catalytic hydrogenations on compounds of different polarity and containing a range of functional groups. The high rate of gas uptake ${ }^{74}$ by VMSs, mentioned above may well play an important role in these reactions.

Tin mediated allylation Metal mediated allylation reactions can be carried out using a range of metals and in solvents as varied as water and ionic liquids, see for example. ${ }^{88}$ It was thus thought of interest to attempt this type of reaction in siloxanes. As this type of reaction has been proven to occur well in water as the sole solvent it was decided not to attempt it in a VOC solvent but to use three reactions: one in a VMS, one biphasic, and one in water. The reason for involving a VMS at all is that, even though the reaction performs well in water alone, the isolation of the product from the reaction mixture still requires the use of a solvent and it was thought that a biphasic system would facilitate the workup.

The tin mediated allylation of benzaldehyde was performed at room temperature over $18 \mathrm{~h}$ in both water and water/M2 (1:1 v/v) and gave moderate yields in both cases (Table 15). On workup, the product from the reaction performed in M2 was isolated by an extraction and separation technique but the reaction in water, when extracted with ethyl acetate, formed a viscous emulsion with the remaining tin which required filtration prior to separation. ${ }^{1} \mathrm{H}-\mathrm{NMR}$ spectroscopy of products from both reactions indicated the presence of benzoic acid. In the biphasic reaction $c a$. $10 \%$ of the acid was present while from the water alone up to $50 \%$ acid was present, presumably the extended reaction time in the presence of water had led to hydrolysis of the initial aldehyde.

Table 15 Allylation reations in water in $\mathrm{M}_{2}$ and in water/ $\mathrm{M}_{2}$

\begin{tabular}{cccc}
\hline \hline Substrate & Solvent & Yield /\% & time \\
\hline \hline \multirow{2}{*}{ Benzaldehyde } & Water & 69 & $18 \mathrm{~h}$ \\
& Water/M & 79 & $18 \mathrm{~h}$ \\
& $\mathrm{M}_{2}$ & 0 & $18 \mathrm{~h}$ \\
\hline \multirow{2}{*}{ 1-hexanal } & Water & 72 & $3 \mathrm{~h}$ \\
& Water/M & 91 & $3 \mathrm{~h}$ \\
& $\mathrm{M}_{2}$ & 0 & $3 \mathrm{~h}$ \\
\hline
\end{tabular}

Allylation of 1-hexanal was carried out in a similar manner to benzaldehyde and after $3 \mathrm{~h}$ the reactions were found to be complete by TLC analysis. In this case no unwanted acid formation occurred indicating that the prolonged reaction time of the benzaldehyde allylation may have resultied in the side product formation. Again, the reaction performed in water required filtration prior to extractive workup. ${ }^{1} \mathrm{H}-\mathrm{NMR}$ spectroscopic analysis of the products revealed the desired product had been formed. In the case of the biphasic reaction some PTC remained and the isolated yield has been corrected for this in Table 15. Diethyl ether was used to isolate the product for the reaction performed in water and the ${ }^{1} \mathrm{H}-\mathrm{NMR}$ spectrum indicated a relatively clean product. The allylation reaction yields were thus marginally improved when using the siloxane solvent for the reaction and the workup procedure was also simplified. 
Carbonyl ligand substitution reactions The displacement of a carbonyl ligand(s) from a carbonyl complex is a common step in the synthesis of transition metal compounds. Syntheses of a number of inorganic compounds, $\mathbf{6 , 7}, \mathbf{8}$, by the displacement of carbonyl ligands was therefore attempted using VMSs as solvents (for the formation of the chromium tricarbonyl complex a small amount of THF was also added to both solvents). In each case, VMSs gave similar results to the traditional organic solvents in facilitating the synthesis of the complexes described below (Table 16). For these reactions replacement of an aromatic solvent, an alkane and an ether has been achieved showing that the siloxanes may have wide applicability.

Table 16 Examples of carbonyl ligand substitution reactions using various solvents

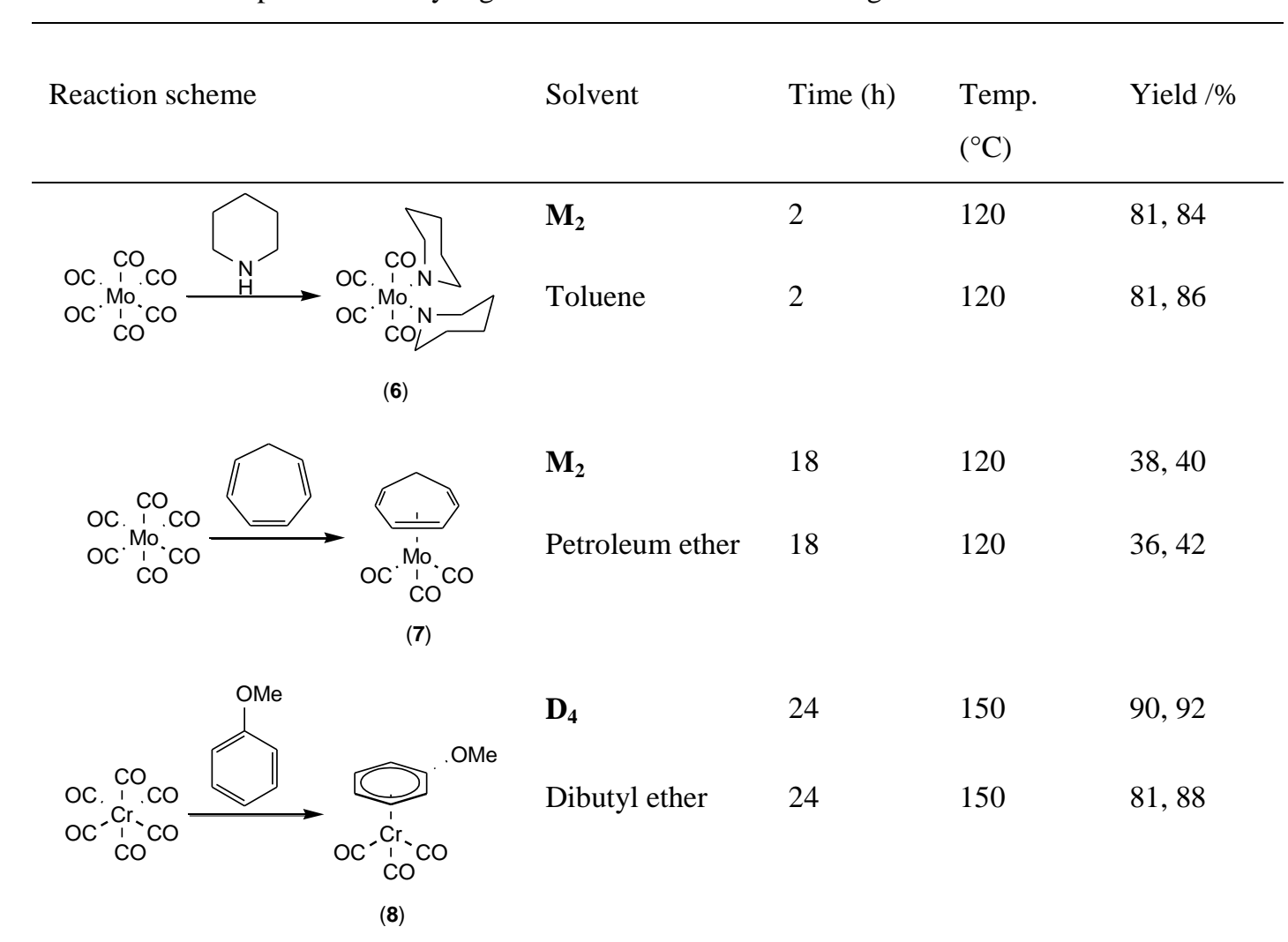

\section{Conclusions}

VMSs are solvents of similar polarities and process performances to alkane solvents. Further to this, their health and environmental impacts are lower than for many solvents. Additionally, VMSs can be substituted for a variety of conventional solvents without the need for specialist equipment, nor adaptation of reagents and procedures. VMSs are currently commercially available on a large scale. Hence, VMSs have the potential to be useful replacements for alkanes, and other solvents, in synthetic chemistry applications, both for organic inorganic transformations.

\section{Experimental}

\subsection{Calculation of environmental health and safety profiles}

The methodology applied by which solvents may be ranked according to their EHS profiles has been documented in the literature, ${ }^{34}$ with a dissemination of the procedure also available online. ${ }^{55}$ To allow a comparison between traditional solvents and VMSs, the parameter previously measuring the severity of any air hazard posed by a solvent, the index 
value of chronic toxicity (unavailable for VMSs), was replaced by POCP. The metrics are not completely dissimilar, but crucially POCP is known for a variety of volatile compounds. Data were obtained from the material safety datasheet (MSDS) of each VMS with the exception those parameters described in Table 2 and Table 3. Worst case scenarios for water persistency have been used for the VMSs, extrapolated from theoretical half-lives in cases where experimentally determined data were not available. ${ }^{21}$

In order to fit the required parameters to the EHS ranking methodology the physical properties and/or legislative status of the solvents are converted, linearly or logarithmically, into an index value for each category (i.e. a zero to one scale). The respective equations to do so are listed in Table 17. If the resulting value exceeds one, or is less than zero, the limits of the index scale were taken instead in accordance with the original method. In instances where the parameter being assessed is not expressed numerically (e.g. solvent risk phrases) the conversion was weighted as previously. ${ }^{55}$ The highest priority parameter available was used to define each category. In cases where equal priority parameters are available, the highest scoring (least green) parameter was applied to give the category index value. Finally a summation of each of the nine effect category index values from the three indicators was performed to give the EHS profile score, as represented in Fig. 1. The entry for PDMS was based on data for the oligomer with a molecular weight of approximately 2000 g. mol ${ }^{-1}$, although all the PDMSs have comparably low EHS profiles. Also with regard to PDMS (2000 g. $\mathrm{mol}^{-1}$ ), the experimental determination of the flash point was only conducted to a temperature of $110^{\circ} \mathrm{C}$, at which point the test was abandoned (as reported in the MSDS issued by the supplier AlfaAesar). Hence, although it may be considerably higher, the flash point of PDMS (2000 g.mol $\left.{ }^{-1}\right)$ was set to $110{ }^{\circ} \mathrm{C}$, accounting for the majority of its EHS profile score.

Table 17 Conversion equations to map VMS parameters (x) onto the component categories (y) of the EHS scale

\begin{tabular}{|c|c|c|c|c|}
\hline Indicator & Category (y) & Priority & Parameter $(\mathrm{x})$ & Conversion ( $\mathrm{x}$ to $\mathrm{y})$ \\
\hline \multirow[t]{4}{*}{ Safety } & \multirow{4}{*}{$\begin{array}{l}\text { Release } \\
\text { potential }\end{array}$} & \multirow[t]{2}{*}{1} & Partial pressure & $\log _{10}(x)-\log _{10}(0.0001)$ \\
\hline & & & /bar & $\log _{10}(10)-\log _{10}(0.0001)$ \\
\hline & & \multirow[t]{2}{*}{2} & Boiling point & $225-x$ \\
\hline & & & $1{ }^{\circ} \mathrm{C}$ & 250 \\
\hline
\end{tabular}

\begin{tabular}{llll}
\hline Safety & $\begin{array}{l}\text { Fire/explosion } \\
\text { risk }\end{array}$ & $1 \quad$ Flash point $/{ }^{\circ} \mathrm{C}$ & $y=\frac{225-x}{200}$
\end{tabular}

2 R-Phrases R10 corresponds to $\mathrm{y}=0.750$

$\mathrm{R} 11$ or $\mathrm{R} 30$ corresponds to $\mathrm{y}=0.875$

$\mathrm{R} 12, \mathrm{R} 15, \mathrm{R} 17$ or $\mathrm{R} 18$ corresponds to $\mathrm{y}=1$

\begin{tabular}{|c|c|c|c|c|}
\hline \multirow[t]{5}{*}{ Safety } & \multirow{5}{*}{$\begin{array}{l}\text { Reaction or } \\
\text { decomposition } \\
\text { potential }\end{array}$} & \multirow[t]{3}{*}{1} & NFPA & NFPA-1 corresponds to $\mathrm{y}=0.600$ \\
\hline & & & Reactivity & NFPA-2 corresponds to $\mathrm{y}=0.800$ \\
\hline & & & & NFPA-3 or NFPA-4 corresponds to $\mathrm{y}=1$ \\
\hline & & 2 & R-Phrases & $\mathrm{R} 5, \mathrm{R} 19, \mathrm{R} 44$ corresponds to $\mathrm{y}=0.800$ \\
\hline & & & & $\mathrm{R} 1, \mathrm{R} 2, \mathrm{R} 3, \mathrm{R} 6$ or $\mathrm{R} 17$ corresponds to $\mathrm{y}=1$ \\
\hline
\end{tabular}

Health $\quad$ Acute toxicity $\quad 1 \quad y=1-\frac{\log _{10} x-\log _{10}(10)}{\log _{10}(100000)-\log _{10}(10)}$

2 EU Classes Xn corresponds to $\mathrm{y}=0.375$

$\mathrm{T}$ corresponds to $\mathrm{y}=0.625$ 
2

$2 \quad$ R-Phrases
$\mathrm{T}+$ corresponds to $\mathrm{y}=0.875$

GK-5 corresponds to $\mathrm{y}=0.125$

GK-4 corresponds to $\mathrm{y}=0.375$

GK-3 corresponds to $\mathrm{y}=0.625$

GK-2 corresponds to $\mathrm{y}=0.875$

GK-1 corresponds to $\mathrm{y}=1$

$\mathrm{R} 20, \mathrm{R} 21$ or $\mathrm{R} 22$ corresponds to $\mathrm{y}=0.375$

R23, R24, R25 or R31 corresponds to $\mathrm{y}=0.625$

$\mathrm{R} 26, \mathrm{R} 27, \mathrm{R} 28, \mathrm{R} 29$ or R32 corresponds to $\mathrm{y}=0.875$

\begin{tabular}{|c|c|c|c|c|}
\hline Health & $\begin{array}{l}\text { Chronic } \\
\text { toxicity }\end{array}$ & 1 & $\begin{array}{l}\text { MAK-CH } \\
/ \mathrm{mg} \cdot \mathrm{m}^{-3}\end{array}$ & $y=1-\frac{\log _{10} x-\log _{10}(0.1)}{\log _{10}(10000)-\log _{10}(0.1)}$ \\
\hline & & 2 & EU Classes & $\mathrm{Xn}$ corresponds to $\mathrm{y}=0.300$ \\
\hline & & & & $\mathrm{T}$ corresponds to $\mathrm{y}=0.500$ \\
\hline & & & & $\mathrm{T}+$ corresponds to $\mathrm{y}=0.700$ \\
\hline & & 2 & GK & GK-5 corresponds to $\mathrm{y}=0.100$ \\
\hline & & & & GK-4 corresponds to $\mathrm{y}=0.300$ \\
\hline & & & & GK-3 corresponds to $y=0.500$ \\
\hline & & & & GK-2 corresponds to $y=0.700$ \\
\hline & & & & GK-1 corresponds to $\mathrm{y}=0.800$ \\
\hline & & 2 & R-Phrases & $\mathrm{R} 31$ or R33 corresponds to $\mathrm{y}=0.500$ \\
\hline & & & & $\mathrm{R} 42$ or $\mathrm{R} 43, \mathrm{y}=0.600$ \\
\hline & & & & $\mathrm{R} 29, \mathrm{R} 32$ or $\mathrm{R} 48$ corresponds to $\mathrm{y}=0.700$ \\
\hline & & & & $\mathrm{R} 40, \mathrm{R} 62, \mathrm{R} 63$ or $\mathrm{R} 64$ corresponds to $\mathrm{y}=0.800$ \\
\hline & & & & $\mathrm{R} 45, \mathrm{R} 46, \mathrm{R} 47, \mathrm{R} 49, \mathrm{R} 60$ or $\mathrm{R} 61$ corresponds to $\mathrm{y}=1$ \\
\hline Health & Irritation & 1 & EU Class & $\mathrm{T}$ corresponds to $\mathrm{y}=0.625$ \\
\hline & & & & $\mathrm{T}+$ corresponds to $\mathrm{y}=0.875$ \\
\hline & & 1 & R-Phrases & $\mathrm{R} 36, \mathrm{R} 37$ or R38 corresponds to $\mathrm{y}=0.625$ \\
\hline & & & & $\mathrm{R} 34$ corresponds to $\mathrm{y}=0.750$ \\
\hline & & & & $\mathrm{R} 35$ corresponds to $\mathrm{y}=0.875$ \\
\hline & & 2 & $\mathrm{LD}_{50}$ (dermal) & $y=1-\frac{\log _{10} x-\log _{10}(5)}{2}$ \\
\hline & & & $/ \mathrm{mg} \cdot \mathrm{kg}^{-1}$ & $y=1-\overline{\log _{10}(50000)-\log _{10}(5)}$ \\
\hline Environment & Persistency & 1 & Aquatic half-life & $y=\frac{\log _{10}(x)-\log _{10}(1)}{1}$ \\
\hline & & & /days & $y-\overline{\log _{10}(100)-\log _{10}(1)}$ \\
\hline Environment & Air hazard & 1 & POCP & $y=\frac{x}{100}$ \\
\hline Environment & Water hazard & 1 & $\begin{array}{l}\mathrm{L}(\mathrm{E}) \mathrm{C}_{50} \text { acute } \\
/ \mathrm{mg}^{-\mathrm{L}^{-1}}\end{array}$ & $y=1-\frac{\log _{10} x-\log _{10}(0.1)}{\log _{10}(1000)-\log _{10}(0.1)}$ \\
\hline & & 2 & R-Phrases & R52 corresponds to $\mathrm{y}=0.375$ \\
\hline & & & & $\mathrm{R} 51$ corresponds to $\mathrm{y}=0.625$ \\
\hline & & & & $\mathrm{R} 50$ corresponds to $\mathrm{y}=0.875$ \\
\hline
\end{tabular}




\subsection{Determination of Kamlet-Taft parameters}

The determination of the Kamlet-Taft parameters $\boldsymbol{\alpha}, \boldsymbol{\beta}$, and $\boldsymbol{\pi}^{*}$ was performed using the following dyes; Nile Red (7diethylamino-3,4-benzophenoxazine-2-one), $p$-nitroaniline, and $N, N$-diethyl- $p$-nitroaniline. The UV-visible spectra of the individual dyes in each VMS were analysed in the following fashion. Solvent polarisability, as described by $\pi^{*}$, was determined using Equation 1 where $v / 10^{3} \mathrm{~cm}^{-1}$ is the wavenumber of the single light absorbance of the dye $N, N$-diethyl$p$-nitroaniline. ${ }^{64}$ Absorbance wavenumbers of dyes in non-VMS solvents were obtained from the literature. ${ }^{64,73}$

Equation 1. $\quad \pi *=\frac{v_{V M S}-v_{C y c l o h e x a r e}}{v_{\text {Dimethylsulphoxide }}-v_{\text {Cyclohexare }}}$

The hydrogen bond basicity ( $\boldsymbol{\beta}$ ) of the VMSs was determined using Equation 2 where $\Delta v / 10^{3} \mathrm{~cm}^{-1}$ is the wavenumber of the single light absorbance of the dye $p$-nitroaniline subtracted from that of $N, N$-diethyl- $p$-nitroaniline. As previously, results derived from the absorbance wavenumbers in non-VMS solvents were obtained from the literature. ${ }^{62,73}$

Equation 2. $\quad \beta=0.76\left(\frac{\Delta v_{V M S}-\Delta v_{\text {Cyclohexare }}}{\Delta v_{\text {Dimethylsulphoxide }}-\Delta v_{\text {Cyclohexare }}}\right)$

The hydrogen bond acidity $(\boldsymbol{\alpha})$ of the VMSs was determined using Equation 3 where $v / 10^{3} \mathrm{~cm}^{-1}$ is the light absorbance wavenumber of the dye Nile Red. ${ }^{72}$ Reichardt's betaine dye was unsuitable due to its low solubility in the VMSs, hence nile red was used instead. The absorbance wavelengths of nile red in traditional organic solvents were also obtained from the literature. ${ }^{72}$

Equation 3. $\quad \alpha=\frac{20.47-(1.95 \pi *)-v_{V M S}}{1.01}$

\subsection{Preparation of organic compounds}

4.3.1 Triethylmethylammonium iodide (1). To a stirred solution of triethylamine $\left(2.0 \mathrm{~cm}^{3}, 0.014 \mathrm{~mol}\right)$ in the chosen solvent $\left(\mathbf{M}_{2}, \mathbf{D}_{4}\right.$, hexane, or tetrahydrofuran, $\left.5.0 \mathrm{~cm}^{3}\right)$ was added methyl iodide $\left(1.5 \mathrm{~cm}^{3}, 0.024 \mathrm{~mol}\right)$. The mixture was stirred at room temperature until $\geq 80 \%$ conversion of triethylamine had occurred. The resultant white precipitate was isolated by suction filtration, and dried in a vacuum oven to give triethylmethylammonium iodide (1), see Table 8 . NMR: $\delta \mathrm{H}\left(400 \mathrm{MHz}\right.$ in $\left.\mathrm{D}_{2} \mathrm{O}\right) 3.23\left(6 \mathrm{H}, \mathrm{q}, \mathrm{NCH}_{2}\right), 2.85\left(3 \mathrm{H}, \mathrm{s}, \mathrm{NCH}_{3}\right), 1.21\left(9 \mathrm{H}, \mathrm{t}, \mathrm{NCH}_{2} \mathrm{CH}_{3}\right) / \mathrm{ppm}$. MS: $\mathrm{m} / z(\mathrm{ESI})$ $116,117\left[\mathrm{NEt}_{3} \mathrm{Me}\right]^{+} ; 359\left[\left(\mathrm{NEt}_{3} \mathrm{Me}\right)_{2} \mathrm{I}\right]^{+}$.

4.3.2 Bicyclo[2.2.1]hept-5-ene-2-carboxylic acid methyl ester (2a) and bicyclo[2.2.1]hept-5-ene-2-carbaldehyde (2b). A solution of freshly cracked cyclopentadiene $\left(0.150 \mathrm{~cm}^{3}, 0.0019 \mathrm{~mol}\right)$ and methyl acrylate $\left(0.175 \mathrm{~cm}^{3}, 0.0019\right.$ mol) or acrolein $\left(0.127 \mathrm{~cm}^{3}, 0.0019 \mathrm{~mol}\right)$ in the chosen solvent $\left(2.1 \mathrm{~cm}^{3}\right)$ was introduced into a sealed vial. The mixture was stirred at $25{ }^{\circ} \mathrm{C}$ in an atmosphere of nitrogen for $24 \mathrm{~h}$. An aliquot $\left(0.05 \mathrm{~cm}^{3}\right)$ was taken by which the stereoisomeric 
ratio of the product, bicyclo[2.2.1]hept-5-ene-2-carboxylic acid methyl ester (2a) or bicyclo[2.2.1]hept-5-ene-2carbaldehyde (2b), could be established by GC analysis (30 m RH-WAX GC column, i.d. $50 \mu$ m, injector and detector teperatures $250{ }^{\circ} \mathrm{C}$, oven temperature $120^{\circ} \mathrm{C}$, total run-time $15 \mathrm{~min}$.) see Table 9 .

Diethyl 2-butylmalonate (3). $n$-Butyl bromide $\left(1.1 \mathrm{~cm}^{3}, 0.01 \mathrm{~mol}\right)$ was added to a solution of diethylmalonate (1.5 mL, $10 \mathrm{mmol})$, 18-crown-6 (0.08 g, $0.3 \mathrm{mmol})$, potassium carbonate (3.32 g, $24 \mathrm{mmol})$, and Adogen-464 (0.1 mL, 0.2 $\mathrm{mmol})$ in a solvent $\left(\mathbf{M}_{\mathbf{2}}, \mathbf{D}_{\mathbf{4}}\right.$, cyclohexane, $\left.25 \mathrm{~mL}\right)$. The mixture was heated to $90^{\circ} \mathrm{C}$ for $4 \mathrm{~h}$ under $\mathrm{N}_{2}$ atmosphere, then by quenching with water $(15 \mathrm{~mL})$. The two layers were separated and the organic layer was washed with saturated aqueous potassium dihydrogen phosphate $(2 \times 15 \mathrm{~mL})$, and the volatiles were removed under reduced pressure. A pale yellow oily residue was obtained in the yields given in Table 10 . NMR: $\delta \mathrm{H}\left(400 \mathrm{MHz}\right.$ in $\left.\mathrm{CDCl}_{3}\right) 1.28(6 \mathrm{H}, \mathrm{t}$, $\left.\mathrm{OCH}_{2} \mathrm{CH}_{3}\right), 4.21\left(4 \mathrm{H}, \mathrm{q}, \mathrm{OCH}_{2} \mathrm{CH}_{3}\right), 4.22(1 \mathrm{H}, \mathrm{t}, \mathrm{CHC}(\mathrm{O})), 1.90\left(2 \mathrm{H}, \mathrm{td}, \mathrm{CHCH}_{2}\right), 1.33\left(2 \mathrm{H}, \mathrm{tt}, \mathrm{CHCH}_{2} \mathrm{CH}_{2}\right), 1.34(2 \mathrm{H}$,

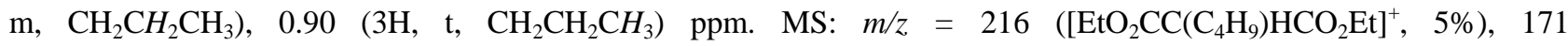
$\left(\left[\mathrm{EtO}_{2} \mathrm{CC}\left(\mathrm{C}_{4} \mathrm{H}_{9}\right) \mathrm{HCO}\right]^{+}, 40 \%\right), 160\left(\left[\mathrm{EtO}_{2} \mathrm{CCHCO}_{2} \mathrm{Et}\right]^{+}, 100 \%\right)$.

4.3.3 Preparation of ethyl-oxo-phenylacetate Calcium hypochlorite $0.715 \mathrm{~g}, 5 \mathrm{mmol}$ ) was added to a stirred solution of ethylmandelate $(1.07 \mathrm{~mL}, 6.62 \mathrm{mmol})$, water $(25 \mathrm{~mL})$, Adogen-464 (0.07 mL, $0.13 \mathrm{mmol})$ in a solvent $\left(\mathbf{M}_{2}\right.$, cyclohexane $25 \mathrm{~mL}$ ) over a period $15 \mathrm{~min}$ while the reaction temperature was maintained below $30^{\circ} \mathrm{C}$. The mixture was stirred at room temperature under $\mathrm{N}_{2}$ atmosphere for $1 \mathrm{~h}$, followed by further $2 \mathrm{~h}$ at $60^{\circ} \mathrm{C}$. The mixture was quenched by saturated sodium chloride solution $(50 \mathrm{~mL})$. The aqueous phase was extracted and washed with additional amount of reaction solvent $(3 \times 15 \mathrm{~mL})$. The combined organic phase was washed with water $(10 \mathrm{~mL})$, dried over magnesium sulphate, and evaporated using rotary evaporator to give the product. ${ }^{1} \mathrm{H}$ NMR spectroscopy and mass spectrometry showed the presence of both the desired product and the starting material in the material isolated, no attempt to separate them was made. Data for the product: $\delta \mathrm{H}\left(400 \mathrm{MHz}\right.$ in $\left.\mathrm{CDCl}_{3}\right) 1.45(3 \mathrm{H}, \mathrm{t}, \mathrm{Ha}), 4.48(2 \mathrm{H}, \mathrm{q}, \mathrm{Hb}), 8.04(2 \mathrm{H}, \mathrm{dddd}, \mathrm{Hc})$, $7.54\left(2 \mathrm{H}\right.$, dddd, Hd), $7.69(1 \mathrm{H}, \mathrm{tt}, \mathrm{He}) / \mathrm{ppm} . \mathrm{MS}: m / z=178\left(\left[\mathrm{PhC}(\mathrm{O}) \mathrm{CO}_{2} \mathrm{Et}\right]^{+}, 7 \%\right), 105\left([\mathrm{PhCOH}]^{+}, 100 \%\right), 77$ $\left(\left[\mathrm{C}_{6} \mathrm{H}_{5}\right]^{+}, 70 \%\right)$.

4.3.4 Cyclohexylcarboxylic acid (5). Thoroughly dried glassware was used together with freshly dried solvents. Magnesium turnings $(0.44 \mathrm{~g}, 18 \mathrm{mmol})$ were added to the chosen anhydrous solvent $\left(\mathbf{M}_{2}\right.$, diethyl ether, tetrahydrofuran, or mixtures of $\mathrm{M}_{2}$ and THF, $3.5 \mathrm{~mL}$ ) and stirred vigorously at room temperature. A solution of cyclohexyl bromide $(2.05 \mathrm{~mL}, 16.6 \mathrm{mmol})$ was dissolved in the same solvent or solvent mixture and added dropwise to the magnesium under an $\mathrm{N}_{2}$ atmosphere at such a rate that a gentle reflux of the solvent was maintained. After the addition was complete, the reaction mixture was heated at $70^{\circ} \mathrm{C}$ for $30 \mathrm{~min}$. The mixture was allowed to cool to room temperature, and an excess of carbon dioxide was bubbled through the reaction vessel with rapid stirring. To the resultant wax was added diethyl ether $(5 \mathrm{~mL})$ and aqueous hydrochloric acid $(2 \mathrm{~N}, 17 \mathrm{~mL})$. The aqueous phase was extracted, washed with diethyl ether ( $3 \times 15 \mathrm{~mL})$, and the combined organic phase was washed with aqueous sodium hydroxide (2N, $5 \mathrm{x} 5 \mathrm{~mL})$. The washings of the organic phase was cooled to $0^{\circ} \mathrm{C}$ and acidified with concentrated aqueous $\mathrm{HCl}$ until precipitation formed. The white precipitate was isolated by suction filtration to give cyclohexyl carboxylic acid in the yields given in table 11. Mpt. $29^{\circ} \mathrm{C}$ (lit. $\left.30^{\circ} \mathrm{C}{ }^{90}\right) \mathrm{NMR}: \delta \mathrm{H}\left(400 \mathrm{MHz}\right.$ in $\left.\mathrm{CDCl}_{3}\right) 2.36\left(1 \mathrm{H}, \mathrm{tt}, \mathrm{CHCO}_{2}\right), 1.71-2.45(4 \mathrm{H}, \mathrm{m}, \mathrm{CH} \mathrm{CH})$, 1.40-1.71 (4H, m, $\left.\mathrm{CH}_{2} \mathrm{CH}_{2} \mathrm{CH}\right), 1.30\left(2 \mathrm{H}, \mathrm{m}, \mathrm{CH}_{2} \mathrm{CH}_{2} \mathrm{CH}_{2} \mathrm{CH}\right), / \mathrm{ppm} . \mathrm{MS}: \mathrm{m} / z=128\left(\left[\mathrm{C}_{6} \mathrm{H}_{11} \mathrm{CO}_{2} \mathrm{H}\right]^{+}, 63 \%\right), 83$ $\left(\left[\mathrm{C}_{6} \mathrm{H}_{11}\right]^{+}, 70 \%\right), 73\left(\left[\mathrm{C}_{2} \mathrm{H}_{4} \mathrm{CO}_{2} \mathrm{H}\right]^{+}, 80 \%\right), 55\left(\left[\mathrm{C}_{4} \mathrm{H}_{7}\right]^{+}, 100 \%\right), 41\left(\left[\mathrm{C}_{3} \mathrm{H}_{5}\right]^{+}, 61 \%\right)$. IR: in nujol $v_{\max } / \mathrm{cm}^{-1} 2500-3094(\mathrm{O}-$ H), 2927 (C-H), $1705(\mathrm{C}=\mathrm{O}), 1451\left(\mathrm{CH}_{2}\right), 1261(\mathrm{C}-\mathrm{O})$.

4.3.5 Hydrogenation of cycloheptene Palladium $(5 \%)$ on carbon $(0.03 \mathrm{~g}, 0.15 \mathrm{mmol})$ was placed in to a two neck flask which was then sealed with septa. Nitrogen gas was flushed through the vessel for ten minutes to remove oxygen. Cycloheptene $(0.6731 \mathrm{~g}, 7 \mathrm{mmol})$ in the appropriate solvent (Methanol or M2, $10 \mathrm{~cm}^{3}$ ) was added via syringe and stirred 
under a hydrogen atmosphere (balloon) at room temperature for 90 minutes. The reaction mixture was filtered and solvent removed under reduced pressure to give cycloheptane. ${ }^{1} \mathrm{H}-\mathrm{NMR}\left(400 \mathrm{MHz}, \mathrm{CDCl}_{3}\right) \delta 1.57(14 \mathrm{H})$

4.3.6 Hydrogenation of nitrobenzene Palladium $(5 \%)$ on carbon $(0.03 \mathrm{~g}, 0.15 \mathrm{mmol})$ was placed in to a two neck flask which was then sealed with septa. Nitrogen gas was flushed through the vessel for ten minutes to remove oxygen. Nitrobenzene $(0.6153 \mathrm{~g}, 5 \mathrm{mmol})$ in the appropriate solvent (Methanol or M2, $10 \mathrm{~cm}^{3}$ ) was added via syringe and stirred magnetically under a hydrogen atmosphere (balloon) at room temperature for 140 minutes. The reaction mixture was filtered and solvent removed under reduced pressure to give phenylamine. ${ }^{1} \mathrm{H}-\mathrm{NMR}\left(400 \mathrm{MHz}, \mathrm{CDCl}_{3}\right) \delta 3.30-3.90$ (2H), 6.68-6.74 (2H), 6.77-6.82 (1H), 7.10-7.22 (2H)

4.3.7 Hydrogenation of benzaldehyde Platinum dioxide $(0.0794 \mathrm{~g}, 0.35 \mathrm{mmol})$ was placed in to a two neck flask which was then sealed with septa. Nitrogen gas was flushed through the vessel for ten minutes to remove oxygen. Benzaldehyde $(0.7494 \mathrm{~g}, 7 \mathrm{mmol})$ and triethylamine $(0.7083 \mathrm{~g}, 7 \mathrm{mmol})$ in the appropriate solvent (Methanol or M2, 10 $\mathrm{cm}^{3}$ ) was added via syringe and stirred magnetically under a hydrogen atmosphere (balloon) at room temperature for 19 h. The reaction mixture was filtered through a silica plug and solvent removed under reduced pressure to give benzyl alcohol. ${ }^{1} \mathrm{H}-\mathrm{NMR}\left(400 \mathrm{MHz}, \mathrm{CDCl}_{3}\right) \delta 4.70(2 \mathrm{H}), 7.30-7.40(5 \mathrm{H})$

4.3.8 Reduction of 1-hexanal using sodium borohydride To a stirred biphasic solution of the appropriate solvent (M2, pdms, hexane or $\left.\mathrm{CH}_{2} \mathrm{Cl}_{2} 10 \mathrm{~cm}^{3}\right)$ water $\left(10 \mathrm{~cm}^{3}\right)$, tetrabutylammonium bromide $(0.2576 \mathrm{~g}$, $0.8 \mathrm{mmol})$, sodium hydroxide $(0.1920 \mathrm{~g}, 4.6 \mathrm{mmol})$ 1-hexanal $(0.8012 \mathrm{~g}, 8 \mathrm{mmol})$, and sodium borohydride $(0.3024 \mathrm{~g}, 8 \mathrm{mmol})$ was added. The mixture was stirred at room temperature for $20-25$ mins. The non-aqueous phase was removed and $2 \mathrm{M} \mathrm{HCl}(\mathrm{aq})$ added to the aqueous phase with until neutral $\mathrm{pH}$ was determined by litmus paper. The aqueous phase was extracted with solvent $\left(10 \mathrm{~cm}^{3}\right)$ the non-aqueous fractions combined, washed with water $\left(2 \times 10 \mathrm{~cm}^{3}\right)$, dried over sodium sulphate $(0.8 \mathrm{~g})$ and evaporated under reduced pressure to give 1-hexanal. ${ }^{1} \mathrm{H}-\mathrm{NMR}\left(400 \mathrm{MHz}, \mathrm{CDCl}_{3}\right) \delta 0.92(3 \mathrm{H}), 1.30$ $1.42(6 \mathrm{H}), 1.55-1.63(2 \mathrm{H}), 3.67(2 \mathrm{H})$.

4.3.9 Reduction of cyclohexanone using sodium borohydride To a stirred biphasic solution of the appropriate solvent (toluene, pentane or MDM, $\left.10 \mathrm{~cm}^{3}\right)$, water $\left(10 \mathrm{~cm}^{3}\right)$, tetrabutylammonium bromide $(0.1610 \mathrm{~g}, 0.5 \mathrm{mmol})$, sodium hydroxide $(0.1200 \mathrm{~g}, 3 \mathrm{mmol})$, cyclohexanone $(0.4907 \mathrm{~g}, 5 \mathrm{mmol})$ and sodium borohydride $(0.1890 \mathrm{~g}, 5 \mathrm{mmol})$ was added. The mixture was stirred at room temperature for 15 mins. The non-aqueous phase was removed and $2 \mathrm{M} \mathrm{HCl}_{(\mathrm{aq})}$ added to the aqueous phase with until neutral $\mathrm{pH}$ was determined by litmus paper. The aqueous phase was extracted with solvent $\left(2 \times 10 \mathrm{~cm}^{3}\right)$, non-aqueous fractions combined, washed with water $\left(2 \times 10 \mathrm{~cm}^{3}\right)$, dried over sodium sulphate $(0.8 \mathrm{~g})$ and evaporated under reduced pressure to give cyclohexanol. ${ }^{1} \mathrm{H}-\mathrm{NMR}\left(400 \mathrm{MHz}, \mathrm{CDCl}_{3}\right) \delta 1.18-1.36$ $(6 \mathrm{H}), 1.75(2 \mathrm{H}), 2.39(2 \mathrm{H}), 3.64(1 \mathrm{H})$.

4.3.10 Benzylation of phthalimide Phthalimide $(1.839 \mathrm{~g}, 12.5 \mathrm{mmol})$, benzyl chloride $(2.000 \mathrm{~g}, 15.8 \mathrm{mmol})$, potassium carbonate $(1.92 \mathrm{~g}, 13.9 \mathrm{mmol})$, tetrabutylammonium bromide $(0.805 \mathrm{~g}, 2.5 \mathrm{mmol})$ in the appropriate solvent $\left(10 \mathrm{~cm}^{3}\right)$ were placed in a flask. The mixture was heated to reflux for $3 \mathrm{~h}$. The reaction was quenched with water $\left(50 \mathrm{~cm}^{3}\right)$ and cooled in ice, filtered, washed with cold water $\left(2 \times 20 \mathrm{~cm}^{3}\right)$ and dried in an oven at $100^{\circ} \mathrm{C}$ for $12 \mathrm{~h}$ to give $\mathrm{N}$-benzyl phthalimide. For the reaction in $\mathrm{CH}_{2} \mathrm{Cl}_{2}$, the reaction mixture was filtered, the $\mathrm{CH}_{2} \mathrm{Cl}_{2}$ removed, the aqueous portion extracted with $\mathrm{CH}_{2} \mathrm{Cl}_{2}\left(2 \times 10 \mathrm{~cm}^{3}\right)$, the $\mathrm{CH}_{2} \mathrm{Cl}_{2}$ washed with water $\left(10 \mathrm{~cm}^{3}\right)$, and the combined organic extracts dried over sodium sulphate $(0.8 \mathrm{~g})$. The solvent was removed under reduced pressure to give N-benzyl phthalimide; ${ }^{1} \mathrm{H}-\mathrm{NMR}$ $\left(400 \mathrm{MHz}, \mathrm{CDCl}_{3}\right) \delta 4.87(2 \mathrm{H}), 7.26-7.26(3 \mathrm{H}), 7.45-7.46(3 \mathrm{H}), 7.71-7.74(3 \mathrm{H}), 7.86-7.88(2 \mathrm{H})$; Mpt. $115-119^{\circ} \mathrm{C}(114-$ $\left.116^{\circ} \mathrm{C},{ }^{91}\right)$

4.3.11 Alkylation of phthalimide Phthalimide $(0.8827 \mathrm{~g}, 6 \mathrm{mmol})$, isobutyl bromide $(1.039 \mathrm{~g}, 7.6 \mathrm{mmol})$, potassium carbonate $(0.922 \mathrm{~g}, 6.7 \mathrm{mmol})$, tetrabutylammonium bromide $(0.3864 \mathrm{~g}, 1.2 \mathrm{mmol})$ in the appropriate solvent $\left(10 \mathrm{~cm}^{3}\right)$ were placed in a flask. The mixture was heated to reflux for $2 \mathrm{~h}$. The reaction was quenched with water $\left(30 \mathrm{~cm}^{3}\right)$ and 
cooled in ice, filtered, washed with cold water $\left(2 \times 10 \mathrm{~cm}^{3}\right)$ and dried in an oven at $100^{\circ} \mathrm{C}$ for $12 \mathrm{~h}$ to give $\mathrm{N}$-isobutyl phthalimide. For the reaction in toluene, the reaction mixture was filtered, the toluene portion separated, the aqueous extracted with toluene $\left(10 \mathrm{~cm}^{3}\right)$, and the combined organic extracts washed with water $\left(10 \mathrm{~cm}^{3}\right)$. These were dried over sodium sulphate $(0.8 \mathrm{~g})$ and solvent removed under reduced pressure to give $\mathrm{N}$-isobutyl phthalimide. ${ }^{1} \mathrm{H}-\mathrm{NMR}(400$ $\left.\mathrm{MHz}, \mathrm{CDCl}_{3}\right) \delta 0.98(6 \mathrm{H}), 2.15(1 \mathrm{H}), 3.54(2 \mathrm{H}), 7.75(2 \mathrm{H}), 7.86(2 \mathrm{H}) ; \mathrm{Mpt}: 94-96^{\circ} \mathrm{C}$.

4.3.12 Allylation of benzaldehyde To a mixture of benzaldehyde (0.2162g, 2.0 mmol), Adogen 464 (0.05 g, 0.2 $\mathrm{mmol})$, in the appropriate solvent system $\left(10 \mathrm{~cm}^{3}\right)$ was added tin powder $(0.2374 \mathrm{~g}, 3 \mathrm{mmol})$. The mixture was stirred at room temperature for $3 \mathrm{~h}$. The reaction was quenched with the appropriate solvent $\left(10 \mathrm{~cm}^{3}\right)$. For the reaction in the M2water binary mixture, the non-aqueous phase was washed twice with water $\left(2 \mathrm{x} 10 \mathrm{~cm}^{3}\right)$, once with saturated sodium chloride solution, dried over sodium sulphate $(0.8 \mathrm{~g})$ and evaporated under reduced pressure to give 1-phenylbut-3-en-1ol. For the reaction in water the product was filtered, washed twice with water $\left(2 \times 10 \mathrm{~cm}^{3}\right)$, once with saturated sodium chloride solution, dried over sodium sulphate $(0.8 \mathrm{~g})$ and evaporated under reduced pressure to give 1-phenylbut-3-en-1ol.

${ }^{1} \mathrm{H}-\mathrm{NMR}\left(400 \mathrm{MHz}, \mathrm{CDCl}_{3}\right) \delta 2.55(3 \mathrm{H}), 4.77(1 \mathrm{H}), 5.18(2 \mathrm{H}), 5.84(1 \mathrm{H}), 7.33(\mathrm{~m}, 5 \mathrm{H})$

4.3.13 Allylation of 1-hexanal To a mixture of 1-hexanal $(0.3004 \mathrm{~g}, 3.0 \mathrm{mmol})$, Adogen $464(0.0 .1392 \mathrm{~g}, 0.3 \mathrm{mmol})$, in the appropriate solvent system [water or water:M2 binary mixture $(1: 1 \mathrm{v} / \mathrm{v}), 10 \mathrm{~cm}^{3}$ ] was added tin powder $(0.5341 \mathrm{~g}$, $4.5 \mathrm{mmol})$. The mixture was stirred at room temperature for $18 \mathrm{~h}$. The reaction was quenched with the appropriate solvent $\left(10 \mathrm{~cm}^{3}\right)$. For the reaction in the M2-water binary mixture, the non-aqueous phase was washed twice with water $\left(2 \times 10 \mathrm{~cm}^{3}\right)$, once with saturated sodium chloride solution, dried over sodium sulphate $(0.8 \mathrm{~g})$ and evaporated under reduced pressure to give 1-nonen-4-ol. For the reaction in water the product was filtered, washed twice with water $(2 \mathrm{x}$ $\left.10 \mathrm{~cm}^{3}\right)$, once with saturated sodium chloride solution, dried over sodium sulphate $(0.8 \mathrm{~g})$ and evaporated under reduced pressure to give 1-nonen-4-ol.

${ }^{1} \mathrm{H}-\mathrm{NMR}\left(400 \mathrm{MHz}, \mathrm{CDCl}_{3}\right) \delta 0.92(3 \mathrm{H}), 1.26-1.41(6 \mathrm{H}), 1.48(2 \mathrm{H}), 2.31(2 \mathrm{H}), 3.67(1 \mathrm{H}), 5.15(1 \mathrm{H}), 5.87(1 \mathrm{H})$

\subsection{Preparation of inorganic compounds}

4.4.1 Bis(piperidine)molybdenum tetracarbonyl (6). Molybdenum hexacarbonyl (0.5g, 1.9 mmol), and piperidine $(2.5 \mathrm{~mL}, 25 \mathrm{mmol})$ were added to the solvent $\left(\mathrm{M}_{2}\right.$ or toluene, $\left.40 \mathrm{~mL}\right)$ and stirred at $120^{\circ} \mathrm{C}$ under $\mathrm{N}_{2}$ atmosphere for $2 \mathrm{~h}$. The mixture was cooled to room temperature, and the resulting precipitate was isolated via suction filtration, washed with light petroleum ether $(5 \mathrm{~mL})$ to give the product in the yields given in table 12 . NMR: $\delta \mathrm{H}\left(400 \mathrm{MHz}\right.$ in $\mathrm{DMSO}^{\left.-\mathrm{d}_{6}\right)}$ $2.69\left(4 \mathrm{H}, \mathrm{m}, \mathrm{CH}_{2} \mathrm{~N}\right), 1.35-1.69\left(8 \mathrm{H}, \mathrm{m}, \mathrm{CH}_{2} \mathrm{CH}_{2}\right) / \mathrm{ppm} . \mathrm{MS}: \mathrm{m} / z=350\left(\left[(\mathrm{Pip})_{2}{ }^{98} \mathrm{Mo}(\mathrm{CO})_{3}\right]^{+}, 51 \%\right), 319$ $\left(\left[(\mathrm{Pip}){ }_{2}{ }^{95} \mathrm{Mo}(\mathrm{CO})_{2}\right]^{+}, 33 \%\right), 306\left(\left[(\mathrm{Pip}){ }_{2}{ }^{98} \mathrm{Mo}(\mathrm{CO})(\mathrm{C})\right]^{+}, 62 \%\right), 282\left(\left[(\mathrm{Py})_{2}{ }^{95} \mathrm{Mo}(\mathrm{CO})\right]^{+}, 100 \%\right), 261\left(\left[(\mathrm{Py})^{98} \mathrm{Mo}(\mathrm{CO})\right]_{3}\right]^{+}$, 61\%), $178\left(\left[\left(\mathrm{C}_{5} \mathrm{H}_{6} \mathrm{~N}\right)^{98} \mathrm{Mo}\right]^{+}, 68 \%\right)$. IR: in nujol $v_{\max } / \mathrm{cm}^{-1} 2927,2867(\mathrm{C}-\mathrm{H}), 1768,1880,1883,2011(\mathrm{C} \equiv \mathrm{O}), 1412-$ $1444\left(\mathrm{CH}_{2}\right), 1000-1265(\mathrm{C}-\mathrm{N})$.

4.4.2 $\eta^{3}$-Cycloheptatriene molybdenum tricarbonyl (7). A solution containing molybdenum hexacarbonyl (2 g, 7.6 mmol) and cycloheptatriene $(4.5 \mathrm{~mL}, 43 \mathrm{mmol})$ in the solvent $\left(\mathbf{M}_{2}\right.$ or petroleum ether $\left.\left(100-120^{\circ} \mathrm{C}\right), 16 \mathrm{~mL}\right)$ was stirred at $150^{\circ} \mathrm{C}$ for $18 \mathrm{~h}$ under an atmosphere of $\mathrm{N}_{2}$. The mixture was cooled to $-78^{\circ} \mathrm{C}$ (dry ice/acetone), and the resultant red precipitate was isolated by suction filtration, and then purified via fractional sublimation. The crude product was heated at $50^{\circ} \mathrm{C}$ in an oil bath under vacuum until no more white crystals of molybdenum hexacarbonyl were seen on the cold finger. After removal of the $\operatorname{Mo}(\mathrm{CO})_{6}$ from the sublimation finger, the temperature of the oil bath was adjusted to $100^{\circ} \mathrm{C}$, and the sublimed purified product was collected in the yields given in Table $12 . \mathrm{NMR}: \delta \mathrm{H}\left(400 \mathrm{MHz}^{2} \mathrm{CDCl}_{3}\right)$ 3.06, $2.49\left(2 \mathrm{H}, \mathrm{dt}, \mathrm{CH}_{2}\right), 3.64\left(2 \mathrm{H}, \mathrm{m}, \mathrm{CHCH}_{2}\right), 4.96\left(2 \mathrm{H}, \mathrm{m}, \mathrm{CHCHCH}_{2}\right), 6.10,\left(2 \mathrm{H}, \mathrm{m}, \mathrm{CHCHCHCH}{ }_{2}\right) / \mathrm{ppm}$. MS: $m / z$ 
$=218\left(\left[{ }^{98} \mathrm{Mo}\left(\eta^{6}-\mathrm{C}_{7} \mathrm{H}_{8}\right)(\mathrm{CO})\right]^{+}, 39 \%\right), 212\left(\left[{ }^{92} \mathrm{Mo}\left(\eta^{6}-\mathrm{C}_{7} \mathrm{H}_{8}\right)(\mathrm{CO})\right]^{+}, 100 \%\right)$. IR: in nujol $v_{\max } / \mathrm{cm}^{-1} 2922 \& 2852(\mathrm{C}-\mathrm{H})$, 1903, 1928, $1993(\mathrm{C} \equiv \mathrm{O}), 1376-146\left(\mathrm{CH}_{2}\right)$.

4.4.3 $\eta^{6}$-Anisole chromium tricarbonyl (8). Chromium hexacarbonyl ( $\left.1 \mathrm{~g}, 4.5 \mathrm{mmol}\right)$, anisole (10 $\left.\mathrm{mL}, 92 \mathrm{mmol}\right)$, and THF (6 mL) were added to the solvent $\left(\mathbf{D}_{\mathbf{4}}\right.$, dibutyl ether, $\left.60 \mathrm{~mL}\right)$ in a flask wrapped by aluminium foil. The flask was evacuated and back-filled with nitrogen nine times. The mixture was heated at $150^{\circ} \mathrm{C}$ for $24 \mathrm{~h}$ then cooled to room temperature, and the solvent was removed carefully under reduced presure. The crude product was redissolved in diethyl ether and th solution filtered through a short pad of silica gel. The solvent was removed via rotary evaporation, to give the purified $\eta^{6}$-Anisole chromium tricarbonyl in the yields given in table 12 . NMR: $\delta \mathrm{H}\left(400 \mathrm{MHz}\right.$ in $\left.\mathrm{CDCl}_{3}\right)$ $3.75\left(3 \mathrm{H}, \mathrm{s}, \mathrm{CH}_{3}\right), 5.58(2 \mathrm{H}, \mathrm{d}, o-\mathrm{CH}), 5.51(2 \mathrm{H}, \mathrm{dd}, m-\mathrm{CH}), 4.91(1 \mathrm{H}, \mathrm{m}, p-\mathrm{CH}) / \mathrm{ppm} . \mathrm{MS}: m / z=245\left(\left[^{53} \mathrm{Cr}\left(\eta^{6}-\right.\right.\right.$ $\left.\left.\left.\mathrm{C}_{6} \mathrm{H}_{5} \mathrm{OCH}_{3}\right)(\mathrm{CO})_{3}\right]^{+}, 67 \%\right), 212\left(\left[{ }^{53} \mathrm{Cr}\left(\eta^{6}-\mathrm{C}_{6} \mathrm{H}_{5}\right)(\mathrm{CO})_{3}\right]^{+}, 71 \%\right)$. IR: in nujol $v_{\max } / \mathrm{cm}^{-1} 2923 \& 2852(\mathrm{C}-\mathrm{H}), 1975,1945$, 1903, $1857(\mathrm{C} \equiv \mathrm{O}), 1528$, (aryl C-C), 1376-1465 $\left(\mathrm{CH}_{3}\right)$.

\section{References}

1. J. H. Clark and S. J. Tavener, Org. Process Res. Dev., 2007, 11, 149-155.

2. K. Alfonsi, J. Colberg, P. J. Dunn, T. Fevig, S. Jennings, T. A. Johnson, H. P. Kleine, C. Knight, M. A. Nagy, D. A. Perry and M. Stefaniak, Green Chem., 2008, 10, 31-36.

3. A. D. Curzons, D. C. Constable and V. L. Cunningham, Clean Products and Processes, 1999, 1, 82-90.

4. D. J. C. Constable, C. Jimenez-Gonzalez and R. K. Henderson, Org. Process Res. Dev., 2007, 11, 133-137.

5. I. M. Smallwood, Solvent Recovery Handbook, Blackwell Science, Oxford, 2002.

6. $\quad$ P. T. Anastas and J. C. Warner, Green Chemistry; Theory and Practice, OUP, Oxford, 1998.

7. E. J. Beckman, J. Supercrit. Fluids, 2004, 28, 121-191.

8. R. S. Oakes, A. A. Clifford and C. M. Rayner, J. Chem. Soc.-Perkin Trans. 1, 2001, 917-941.

9. W. Leitner, Acc. Chem. Res., 2002, 35, 746-756.

10. I. T. Horvath, Acc. Chem. Res., 1998, 31, 641-650.

11. A. P. Dobbs and M. R. Kimberley, J. Fluor. Chem., 2002, 118, 3-17.

12. L. P. Barthel-Rosa and J. A. Gladysz, Coord. Chem. Rev., 1999, 190-192, 587-605.

13. EPA 40 CFR 51.100(s), Definition of volatile organic compounds (VOC), 2009, http://www.epa.gov/ttn/naaqs/ozone/ozonetech/def_voc.htm. (accessed 1 Sept 2011).

14. U.S. Environmental Protection Agency, Significant New Alternatives Policy (SNAP) Final Summary http://www.epa.gov/ozone/snap/fact.html, accessed June 25th 2012

15. Council directive 1999/13/EC, on the limitation of emissions of volatile organic compounds due to the use of organic solvents in certain activities and installations, 1999.; available from http://eurlex.europa.eu/LexUriServ/LexUriServ.do?uri=OJ:L:1999:085:0001:0022:EN:PDF (accessed 1 Sept. 2011)

16. Ullmann's Encyclopedia of Industrial Chemistry, ed. B. Elvers, S. Hawkins, W. Russey and G. Schulz, WileyVCH, Weinheim, 7th edn., 2005, vol. A24.

17. M. A. Brook, Silicon in Organic, Organometallics, and Polymer Chemistry, John Wiley and Sons, New York, 2000.

18. Silicon-Containing Polymers, eds. R. G. Jones, W. Ando, and J. Chojnowski, Kluwer Academic Publishers, Dordrecht, 2000.

19. Silicones and Silicone-Modified Materials; ACS Symposium Series 729, eds. S. J. Clarson, J. J. Fitzgerald, M. J. Owen, and S. D. Smith, American Chemical Society, Washington DC, 2000. 
20. M. Butts, J. Cella, C. D. Wood, G. Gillette, R. Kerboua, J. Leman, L. Lewis, S. Rubinsztajn, F. Schattenmann, J. Stein, D. Wicht, R. S. and J. Wengrovius, Kirk-Othmer Encyclopedia of Chemical Technology, ed. A. Seidel, Reinhold Publishing Co., New York, 5th edn., 2006, vol. 22.

21. The Handbook of Environmental Chemistry, vol. 3 part H: Organosilicon Materials, ed. G. Chandra, SpringerVerlag, Berlin, 1997.

22. Catalysed Direct Reactions of Silicon, ed. K. M. Lewis and D. G. Rethwisch, Elsevier Science Publishers B.V., Amsterdam, 1993.

23. D. W. Williams, Volatile Methyl Siloxanes: Environmetally Sound Solvent Systems in ACS Symposium Series, 2000, 767, 244-257.

24. D. J. Heldebrandt, H. N. Witt, S. M. Walsh, T. Ellis, J. Rauscher and P. G. Jessop, Green Chem., 2006, 8, 807815.

25. H. B. Lazrek, D. Ouzebla, L. Baddi, and J. J. Vasseur, Nucleosides, Nucleotides and Nucleic Acids, 2007, 26, 1095-1098.

26. J. L. Krinsky, L. L. Anderson, and R. G. Bergman, Inorg. Chem., 2008, 47, 1053-1066.

27. M. M. Clark, W. W. Brennessel and P. L. Holland, Acta Crystallogr. 2009, E65, m391.

28. The Analytical Chemistry of Silicones, ed. A. L. Smith, John Wiley and Sons, New York, 1991.

29. CRC Handbook of Chemistry and Physics, ed. D. R. Lide, Taylor and Francis, Bota Raton, 88th edn., 2008.

30. Dow Corning Product data sheet, http://www1.dowcorning.com/DataFiles/090007c88020e2df.pdf

31. H. Fox, P. Taylor and W. Zisman, Ind. Eng. Chem., 1947, 39, 1401-1409.

32. M. Palczewska-Tulinska and P. Oracz, J. Chem. Eng. Data 2005, 50, 1711-1719.

33. J. J. Jasper, J. Phys. Chem. Ref. Data, 1972, 1, 841-1009.

34. C. Capello, U. Fischer and K. Hungerbühler, Green Chem., 2007, 9, 927-934.

35. J. V. Sousa, P. C. McNamara, A. E. Putt, M. W. Machado, D. C. Surprenant, J. L. Hamelink, D. J. Kent, E. M. Silberhorn and J. F. Hobson, Environ. Toxicol. Chem., 1995, 14, 1639-1647.

36. R. G. Meeks, D. G. Stump, W. H. Siddiqui, J. F. Holson, K. P. Plotzke and V. L. Reynolds, Reprod. Toxicol., 2007, 23, 192-201.

37. W. H. Siddiqui, D. G. Stump, K. R. Plotzke, J. F. Holson and R. G. Meeks, Reprod. Toxicol., 2007, 23, $202-$ 215.

38. A. L. Quinn, J. M. Regan, J. M. Tobin, B. J. Marinik, J. M. McMahon, D. A. McNett. C. M. Sushynski, S. D. Crowfoot, P. A. Jean and K. P. Plotzke, Toxicol. Sci. 2007, 96, 145-153.

39. B. He, S. Rhodes-Brower, M. R. Miller, A. E. Munson, D. R. Germolec, V. R. Walker, K. S. Korach and B. J. Meade, Toxicol. Appl. Pharm., 2003, 192, 254-261.

40. A. Kierkegaard, R. van Egmond and M. S. McLachlan Environ. Sci. Technol., 2011, 45, 5936-5942.

41. S. Genualdi, T. Harner, Y. Cheng, M. MacLeod, K. M. Hansen, R. van Egmond, M. Shoeib and S. C. Lee, Environ. Sci Technol., 2011, 45, 3349-3354.

42. M. S. McLachan, A. Kierkegaard, K. M. Hansen, R. van Egmond, J. H. Christensen and C. A. Skjoth, Environ. Sci. Technol., 2010, 44, 5365-5370.

43. A. Kierkegaard and M.S. McLachlan, J. Chromatogr. A, 2010, 1217, 3557-3560.

44. N. A. Warner, A. Evenset, G. Christensen, G. W. Gabrielsen, K. Borgå, H. Leknes, Environ. Sci. Technol. 2010, 44, 7705-7710.

45. P. H. Howard and D. C. G. Muir, Environ. Sci. Technol., 2010, 44, 2277-2285.

46. Z. Zhang, H. Qi, N. Ren, Y. Li, D. Gao, K. Kannan, Arch. Environ. Contam. Toxicol., 2011; $60,204$. 
47. T. Brown and F. Wania, Environ. Sci. Technol., 2008, 42, 5202-5209.

48. Environment Canada; Health Canada Screening assessment for the challenge. Decamethylcyclopentasiloxane (D5). Environment Canada: 2008. http://www.ec.gc.ca/substances/ese/eng/challenge/batch2/batch2_541-026_en.pdf (accessed 1/9/2011).

49. L. Hughes, D. Mackay, D. E. Powell, J. Kim, Chemosphere, 2012, 87, 118-124.

50. Brooke, D. N.; Crookes, M. J.; Gray, D.; Robertson, S. Environmental Risk Assessment Report: Octamethylcyclotetrasiloxane; Environment Agency of England and Wales: Bristol, U.K., 2009; http://publications.environment-agency.gov.uk/pdf/SCHO0309BPQZ-e-e.pdf

51. Brooke, D. N.; Crookes, M. J.; Gray, D.; Robertson, S. Environmental Risk Assessment Report: Decamethylcyclopentasiloxane; Environment Agency of England and Wales: Bristol, U.K., 2009; http://publications.environment-agency.gov.uk/PDF/SCHO0309BPQX-E-E.pdf

52. Brooke, D. N.; Crookes, M. J.; Gray, D.; Robertson, S. Environmental Risk Assessment Report: dodecamethylcyclohexasiloxane; Environment Agency of England and Wales: Bristol, U.K., 2009; http://publications.environment-agency.gov.uk/pdf/SCHO0309BPQY-e-e.pdf

53. D. Graiver, K. W. Farminer and R. Narayan, J. Polym. Environ., 2003, 11, 129-136.

54. J. C. Carpenter, J. A. Cella and S. B. Dorn, Environ. Sci. Technol., 1995, 29, 864-868.

55. H. Sugiyama, U. Fischer and K. Hungerbühler, The EHS Tool, ETH Zurich, Safety \& Environmental Technology Group, Zurich, 2006, http://www.sust-chem.ethz.ch/tools, (accessed 22/9/2011).

56. S. Xu and B. Kropscott, Anal. Chem., 2012, 84, 1948-1955.

57. R. G. Dewent, M. E. Jenkin, S. M. Saunders and M. J. Pilling, Atmospheric Environment, 1998, 32.

58. R. Sommerlade, H. Parlar, D. Wrobel and P. Kochs, Environ. Sci. Technol., 1993, 27, 2435-2440.

59. R. Atkinson, E. C. Tuazon, E. S. C. Kwok, J. Arey, S. M. Aschmann and I. Bridier, J. Chem. Soc.-Faraday Trans., 1995, 91, 3033-3039.

60. R. R. Buch, T. H. Lane, R. B. Annelin and C. L. Frye, Environ. Toxicol. Chem., 1984, 3, $215-222$.

61. C. Reichardt and T. Welton, Solvents and Solvent Effects in Organic Chemistry, $4^{\text {th }}$ edn. VCH Wiley, Weinheim, 2010.

62. M. J. Kamlet and R. W. Taft, J. Am. Chem. Soc., 1976, 98, 377-383.

63. R. W. Taft and M. J. Kamlet, J. Am. Chem. Soc., 1976, 98, 2886-2894.

64. M. J. Kamlet, J. L. Abboud and R. W. Taft, J. Am. Chem. Soc., 1977, 99, 6027-6038.

65. M. J. Kamlet, J. L. M. Abboud, M. H. Abraham and R. W. Taft, J. Org. Chem., 1983, 48, 2877-2887.

66. J. E. Mark, H. R. Allcock and R. West, Inorganic Polymers, OUP, New York, 2005.

67. Silicones and Silicone-Modified Materials, ACS Symposium Series, 729. Eds. S. J. Clarson, J. J. Fitzgerald, M. J. Owen and S. D. Smith, American Chemical Society, Washington D.C., 2000.

68. K. Izod, C. Wills, W. Clegg and R. W. Harrington, Organometallics, 2006, 25, 5326-5332.

69. K. Izod, S. T. Liddle, W. McFarlane and W. Clegg, Organometallics, 2004, 23, 2734-2743.

70. S. Blair, K. Izod and W. Clegg, Inorg. Chem., 2002, 41, 3886-3893.

71. W. Clegg, S. Doherty, K. Izod, H. Kagerer, P. O'Shaughnessy and J. M. Sheffield, J. Chem. Soc.-Dalton Trans., 1999, 1825-1829.

72. R. S. Moog, D. D. Kim, J. J. Oberle and S. G. Ostrowski, J. Phys. Chem. A, 2004, 108, 9294-9301.

73. L. Crowhurst, P. R. Mawdsley, J. M. Perez-Arlandis, P. A. Salter and T. Welton, Phys. Chem. Chem. Phys., 2003, 5, 2790-2794.

74. P. Cannon, L. E. St. Pierre and A. A. Miller, J. Chem. Eng. Data, 1960, 5, 236. 
75. P. G. T. Fogg and W. Gerrard, Solubility of Gases in Liquids, John Wiley and Sons, New York, 1991.

76. W. Gerrard, Gas Solubilities, Pergamon Press, Oxford, 1980.

77. R. J. Wilcock, M. J. L. and R. Battino, Fluid Phase Equilibria, 1978, 2, 225.

78. H. P. Suerken, J. Amort, H. Hanisch and H. van der Maas, US Pat., 4649220, 1987.

79. E. D. Hughes and C. K. Ingold, Trans. Faraday Soc., 1941, 37, 657.

80. J. A. Berson, Z. Hamlet and W. A. Mueller, J. Amer. Chem. Soc., 1962, 84, 297.

81. R. Bini, C. Chiappe, V. L. Mestre, C. S. Pomelli and T. Welton, Org. Biomol. Chem., 2008, 6, 2522-2529.

82. (a) E. V. Dehmlow, S. S. Dehmlow, Phase-Transfer Catalysis, $3^{\text {rd }}$ ed, VCH, Weinheim, 1993; (b) C. M. Starks, C. L. Liotta, M. Halpern, Phase-Transfer Catalysis: Fundamentals, Applications and Industrial Perspectives, Chapman \& Hall, New York, 1994; (c) Y. Sasson and R. Neumann R. (Eds.), Handbook of Phase Transfer Catalysis, Blackie, London, 1997; (d) J.-J. Jwo, Catal. Rev. 2003, 45, 397.

83. (a) M. Makosza, Pure Appl. Chem., 2000, 72, 1399; (b) G. D. Yadav, Topics in Catal. 2004, $29,145$.

84. Silicone Surfactants: Surfactant Science Series vol. 86, Ed. R. M. Hill, Marcel Dekker, Inc., New York, 1999.

85. A. Da Settimo, G. Primofiore, F. Da Settimo, F. Simorini, C. La Motta, A. Martinelli and E. Boldrini, Eur. J. Med. Chem., 1996, 31, 49-58. M. E. Langmuir, J.-R. Yang, A. M. Moussa, R. Laura and K. A. LeCompte, Tetrahedron Lett., 1995, 36, 3989-3992. X. Guo, F. S. Kim, S. A. Jenekhe and M. D. Watson, J. Amer. Chem. Soc., 2009, 131, 7206-7207.

86. J. Jaśkowska and P. Kowalski, J. Hetero. Chem., 2008, 45, 1371-1375.

87. F. Ganachaud and S. Boileau in Handbook of Ring-Opening Polymerization, eds. P. Dubois, O. Coulembier and J.-M. Raquez, Wiley-VCH, Weinheim, 2009, pp. 65-96.

88. F. Gao, Q.-H. Chen and F.- P. Wang, Tet. Lett., 2009, 50, 5270.

89. M. C. Law, K.-Y. Wong and T. H. Chan, Green Chem., 2002, 4, 161-164. Z. Zha, Y. Wang, G. Yang, L. Zhang and Z. Wang, Green Chem., 2002, 4, 578-580. M. K. Chaudhuri, S. K. Dehury and S. Hussain, Tetrahedron Lett., 2005, 46, 6247-6251.

90. E. G. E. Hawkins, D. J. G. Long, and F. W. Major, J. Chem. Soc., 1955, 1462-1468.

91. B. Mokhtari, R. Azadi, and A. Azhdari, Chinese Chem. Lett. 2010, 21, 171-174. 